\title{
Formation Mechanism of a Low-Level Jet during the Passage of Typhoon Ma-on (2004) over the Southern Kanto District
}

\author{
Wataru MASHIKO \\ Meteorological Research Institute, Japan Meteorological Agency, Tsukuba, Japan
}

(Manuscript received 29 September 2006, in final form 1 November 2007)

\begin{abstract}
On 9 October 2004, Typhoon Ma-on hit the southern Kanto district in eastern Japan. Strong winds were observed in the left-rear quadrant of Ma-on near the typhoon center during its passage over the southern Kanto district in spite of the rapid translation speed of about $70 \mathrm{~km} \mathrm{~h}^{-1}$.

Numerical simulations of Ma-on were performed using a nonhydrostatic model with a horizontal grid spacing of $2 \mathrm{~km}$. The simulation results showed that the strong winds on the left-rear quadrant of Maon were low-level phenomena after landfall. The low-level jet (LLJ) associated with the observed strong winds formed over the Sagami bay just after the typhoon center had passed. The typhoon moved over the pre-existing low-level cold air in the Kanto region. When the typhoon center reached the Sagami bay, the northerly flow of the low-level cold air formed a narrowed channel between the typhoon center and the Kanto Mountains in the west of the Kanto plain. The LLJ corresponded to the outflow response from the narrowed channel to the Sagami bay. Trajectory analysis illustrated that the parcels which passed through the LLJ traveled southward parallel to the Kanto Mountains. When they passed near the Tanzawa Mountains at the southern tip of the Kanto Mountains, significant subsidence, spreading and acceleration occurred toward the Sagami bay. The horizontal momentum budget analysis and diagnostic evaluation of pressure gradient force (PGF) revealed that the LLJ was mainly supported by the large-scale southward PGF due to Ma-on. However, locally generated mesoscale forcing due to the decreasing depth of cold layer worked around the exit of the narrowed channel of the cold air. Thus, we conclude that the dynamics and structure of the LLJ were close to those of "gap wind". The sensitivity experiments showed that the low-level cold air as well as the relative position between the high mountainous topography and the typhoon was essential for the LLJ formation.
\end{abstract}

\section{Introduction}

A landfalling tropical cyclone often has remarkable asymmetric structure (e.g., Powell 1987; Chen and Yau 2003; Knupp et al. 2006). The innercore of tropical cyclone is one of the most destructive area even after the landfall (e.g., Powell et al. 1991; Wakimoto and Black 1994; Powell and Houston 1996, 1998; Blackwell 2000). In the mid-

Corresponding author: Wataru Mashiko, Meteorological Research Institute, Japan Meteorological Agency, 1-1 Nagamine, Tsukuba, Ibaraki 305-0052, Japan.

E-mail: wmashiko@mri-jma.go.jp

(C)2008, Meteorological Society of Japan latitude area like Japan, the asymmetric structure of the landfalling tropical cyclone is often attributable to not only the nonuniform surface conditions including the topography, but also the extratropical process (e.g., Klein et al. 2000; Kitabatake 2002), the environmental wind shear (e.g., Jones 1995; Bender 1997; Frank and Ritchie 2001; Black et al. 2002) and the storm translation (e.g., Powell 1982; Shapiro 1983; Frank 1984). The asymmetry may be relevant to induce severe weather such as hazardous winds, torrential rainfall, and even tornadoes at preferred locations. In order to improve the forecasting skill and prevent disasters, it is important to understand the detailed structure of landfalling tropical cyclone and physical mecha- 
nism of the extreme event associated with tropical cyclone.

Wakimoto and Black (1994) surveyed the intense damage caused by the passage of the innercore region of Hurricane Andrew (1992) over southern Florida. The strength of the surface winds was assessed with an F-scale rating (Fujita 1981) and the strongest wind was estimated at F3 around the east side of the eyewall. They hypothesized that increased surface roughness due to the hurricane landfall contributed to a surface wind enhancement although in most cases the increase in roughness reduces surface winds (Powell 1982, 1987; Powell et al. 1991). Powell and Houston (1998) conducted the damage survey of landfalling hurricanes and showed that structures exposed on hillsides and hilltops were more susceptible to wind damage than those located at lower elevations. They suggested that the strong winds due to the topographic effects should be assessed by the mesoscale model. Knupp et al. (2006) showed that the cold stable offshore flow within stratiform precipitation exhibited a modest jet using the observational data during the landfall of Tropical Storm Gabrielle (2001) on the western Florida coast. They indicated that the flow appeared to behave like a density current. Fujibe et al. (1995) investigated the features of surface wind fields in the southern part of the Kanto plain during the passage of Typhoon Wayne (1989) under the extratropical process. They revealed that low-level northerly jet existed in the rear side of the mesoscale front near the typhoon center. Fujibe et al. (2006) showed that the strong winds on the left-rear quadrant of Typhoon Mirelle (1991) coincided with a region of low temperature in a rainband. They inferred that dry air intrusion to the west of the typhoon caused evaporative cooling and generated the cold-air surge. However, insufficient observation in terms of space and time precludes detailed analysis of the structure and mechanism of mesoscale phenomenon.

In the meanwhile, numerical simulation of tropical cyclone with a high-resolution model has progressed significantly in recent years. Numerical studies (Liu et al. 1997; Chen and Yau 2003; Yau et al. 2004) showed the asymmetric features of landfalling hurricane and revealed that they were related to the intensity of hurricane. These studies mainly showed the conceptional features of tropical cyclone. Saito (1994) successfully simulated a strong downslope wind 'Yamaji-kaze' in the lee of the Shikoku Mountains caused by Typhoon Mireille (1991) using the $2.5 \mathrm{~km}$ horizontal resolution nonhydrostatic model. They revealed that the environmental field produced by the typhoon and the orography were essential for the downslope wind, which occurred about 200-300 km distant from the typhoon center.

The actual phenomena of severe mesoscale events near the center of tropical cyclone, however, have not yet targeted. This is partly because numerical reproduction for those events requires almost perfect forecast of the storm track and enough model resolution for the detailed innercore structure.

This paper shows the successfully simulated mesoscale fields observed near the storm center of Typhoon Ma-on (2004), which caused hazardous winds in the left-rear quadrant of the rapid translating typhoon over the southern portion of the Kanto plain. The strong winds occurred near the mountains on the western side of the Kanto plain. The objectives of this study are to elucidate the structure of landfalling Ma-on and the formation mechanism of a low-level jet (LLJ) associated with the observed surface strong winds with cold air mass, and try to relate it to the well-known meteorological phenomenon of "gap wind".

Gap wind (or gap flow) is the orographically-influenced strong wind which is commonly associated with the low-level cold air. Strong ageostrophic winds often develop in coastal gaps or channels when an along-gap pressure gradient is created by the approach of a synoptic-scale disturbance. A number of observational and theoretical studies have documented the structures and dynamics of gap wind (or gap flow) (e.g., Arakawa 1969; Lackmann and Overland 1989; Colle and Mass 2000; Liu et al. 2000; Sharp and Mass 2002). The hazardous winds usually occur near the exit of the gap. Lower stable layer and long narrow gap favor the formation of the gap flow (Overland 1984). Colle and Mass (2000) revealed the detailed structures of easterly gap wind through the Strait of Juan de Fuca using high-resolution Doppler radar and aircraft data. They showed that strongest winds were located near the exit of the gap where the gap flow spread and got shallower as it became less constrained by surrounding terrain. This feature of the gap wind was simulated well by the highresolution model in other cases (Liu et al. 2000; Sharp and Mass 2002). Liu et al. (2000) investigated the dynamics of the LLJ in the valley in Iran 
by the numerical simulation. They indicated that the cold air supply was a key factor in the formation of the LLJ. Colle and Mass (2000) conducted trajectories analysis from the simulation results. They showed that much of the low-level acceleration and subsidence at the gap exit was forced by downslope flow off the surrounding terrain. As other studies (Arakawa 1969, 2006; Saito 1992) indicated, the strong wind events on the gap or col of the complex mountain terrain often attribute to the combination mechanism of the gap flow and the downslope winds.

The contents of this paper are organized in the following manner. Section 2 presents a synoptic description of this event. Characteristics of the observed mesoscale fields are shown in Section 3. Section 4 describes the numerical models used in this study and brief verification of the simulation results. Section 5 presents the structure change of Ma-on after landfall by the simulation results and shows that the LLJ is associated with cold air flow which forms gap wind structure. Section 6 shows the simulated detailed structure of the LLJ and explores the dynamics of this event analyzing the momentum budget along the trajectory. In Section 7, the sensitivity experiments about the topography and low-level cold air are presented. Summary and conclusions are presented in the final section.

\section{Synoptic description}

On 9 October 2004, a strong typhoon Ma-on hit the Kanto region in eastern Japan and caused wind damage and flooding there. Figure 1 shows the best track analysis of Ma-on by Japan Meteorological Agency (JMA). The typhoon was initially organized in the east of Philippine Islands on the western Pacific Ocean at 1500 Japan Standard Time (JST $=$ UTC +9 hours) on 3 October. Ma-on moved northward slowly and developed explosively with $55 \mathrm{hPa}$ deepening in 30 hours which commenced around 2100 JST on 6 October. After that, Ma-on turned north-northeastward and moved rapidly with the translation speed of about $70 \mathrm{~km} \mathrm{~h}^{-1}$ around Japan under the influence of the southwesterly jet stream at the upper level.

When Ma-on landed on eastern Japan at 1600 JST on 9 October, the minimum sea level pressure (MSLP) was $950 \mathrm{hPa}$ and the estimated maximum 10 -min sustained wind was 80 knot. The surface synoptic weather charts for 0900 JST on 9 October 2004 is shown in Fig. 2. The stationary front ex-

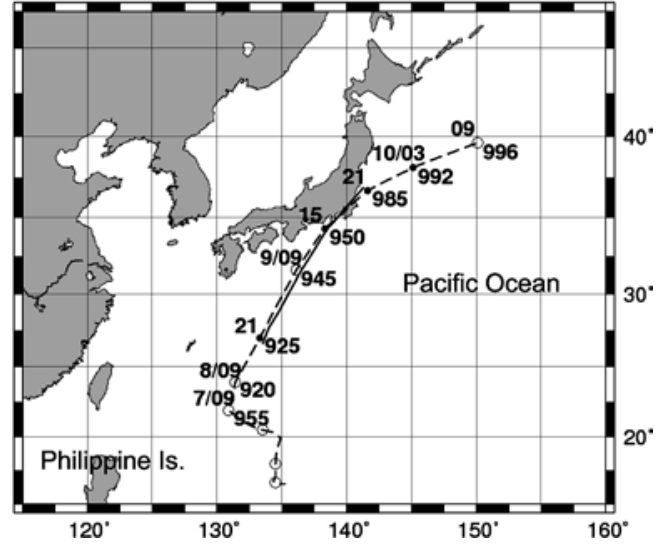

Fig. 1. The best track analysis of Typhoon Ma-on (2004) by Japan Meteorological Agency (broken line). Open circles show the locations of the typhoon center at every 09 JST. Numerals on the right show MSLP (hPa), and left ones indicate the corresponding time (date/hour or hour). Solid line shows the track of the 24 hours-simulation result from 2100 JST on 8 October (See Section 4.2).

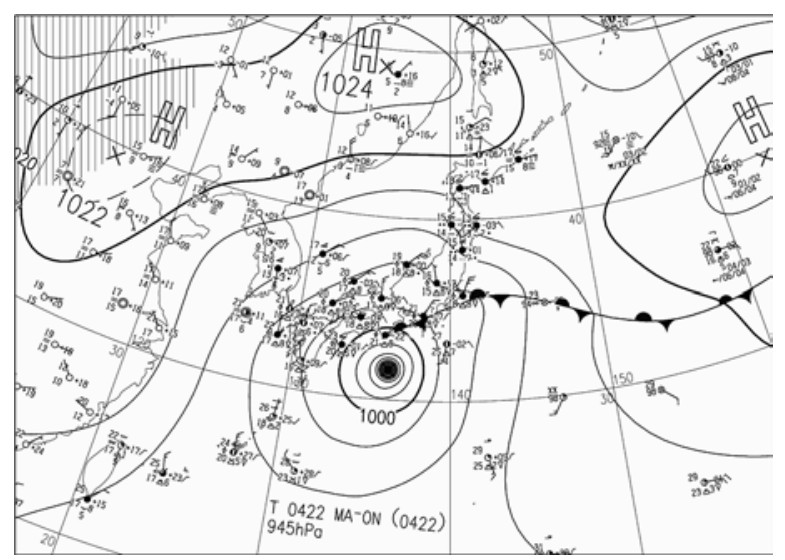

Fig. 2. The Surface synoptic weather chart at 0900 JST on 9 October 2004.

isted to the south of eastern Japan, and the lowlevel synoptic winds were the northeasterly with cold air in eastern Japan until the passage of Maon. 


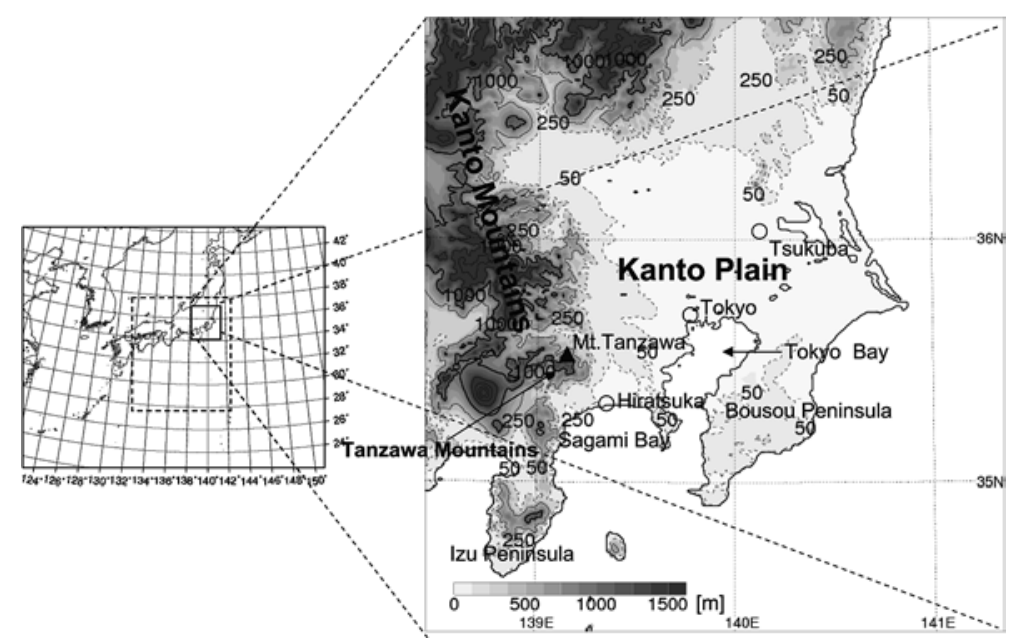

Fig. 3. Right figure is topography and geographical locations around the Kanto plain. The solid contour interval of elevation is $500 \mathrm{~m}$, with dashed lines of 50 and $250 \mathrm{~m}$ height. Left figure corresponds to the model domain and the rectangle framed by the dashed line shows the inner model domain (see Section 4.1).

\section{Mesoscale analysis based on observa- tional data around the Kanto plain}

\subsection{Geographical features around the Kanto plain}

The geographical map around the Kanto plain is shown in Fig. 3. The Kanto plain is located in eastern Japan. On the western side of the Kanto plain, Kanto Mountains that are elevated more than $1000 \mathrm{~m}$ constantly run from north to south. At the southern tip, Tanzawa Mountains including Mt Tanzawa $(1567 \mathrm{~m})$ are located, while the mountain ranges continue northward into northern Japan. Sea surface temperature is low at the eastern coast of the Kanto plain since the cold subarctic ocean current is flowing southward along the coast.

\subsection{Time evolution of mesoscale fields around the Kanto plain during the passage of Ma-on}

Figures 4a-e show the observed surface winds and temperature by AMeDAS (Automated Meteorological Data Acquisition System) between 1600 JST and 1900 JST on 9 October 2004. As noted in Section 2, the stationary front existed to the south of the Kanto plain before Ma-on approached the Kanto plain. The Kanto plain was broadly occupied by cold air (about $17^{\circ} \mathrm{C}$ ) with northeasterly winds except for the southern portion of the Bousou peninsula (Fig. 4a).

After Ma-on made a landfall on the Izu peninsu- la at 1600 JST with the MSLP of $950 \mathrm{hPa}$, it passed through the Sagami bay and the Tokyo bay to the Pacific Ocean with a rapid decaying stage. When the typhoon reached near Tokyo at 1800 JST (Fig. 4d), the MSLP was $980 \mathrm{hPa}$. The cold air mass with northeasterly winds was almost sustained although the typhoon center passed through the southern Kanto region. The typhoon center was also almost covered with the cold air mass. The warm sector with the southerly winds reached only to the southern or eastern part of the Bousou peninsula. At the edge of it, the mesoscale front formed with large temperature gradient (about 7 ${ }^{\circ} \mathrm{C} / 20 \mathrm{~km}$ at $1700 \mathrm{JST}$ ) and strong wind shear. The mesoscale front like this is often observed in the Kanto plain when tropical cyclone is approaching (Fujibe 1992; Fujibe et al. 1995).

The wind direction in the cold air mass under the translating typhoon was mainly northeasterly. In the western side of the Kanto plain, the wind direction turned parallel (northerly) to the mountains orientation shown by the contour of $250 \mathrm{~m}$ height until 1730 JST (Figs. 4a-c). The strong northerly winds (10-min average) of about $20 \mathrm{~m}$ $\mathrm{s}^{-1}$ were observed on the north and the west side of the typhoon from 1700 JST to 1800 JST (Figs. $4 \mathrm{~b}-\mathrm{d}$ ) when the typhoon center was located on the Sagami bay to Tokyo bay. The area of those strong winds corresponds to the left-rear quadrant of the moving typhoon in spite of its rapid transla- 

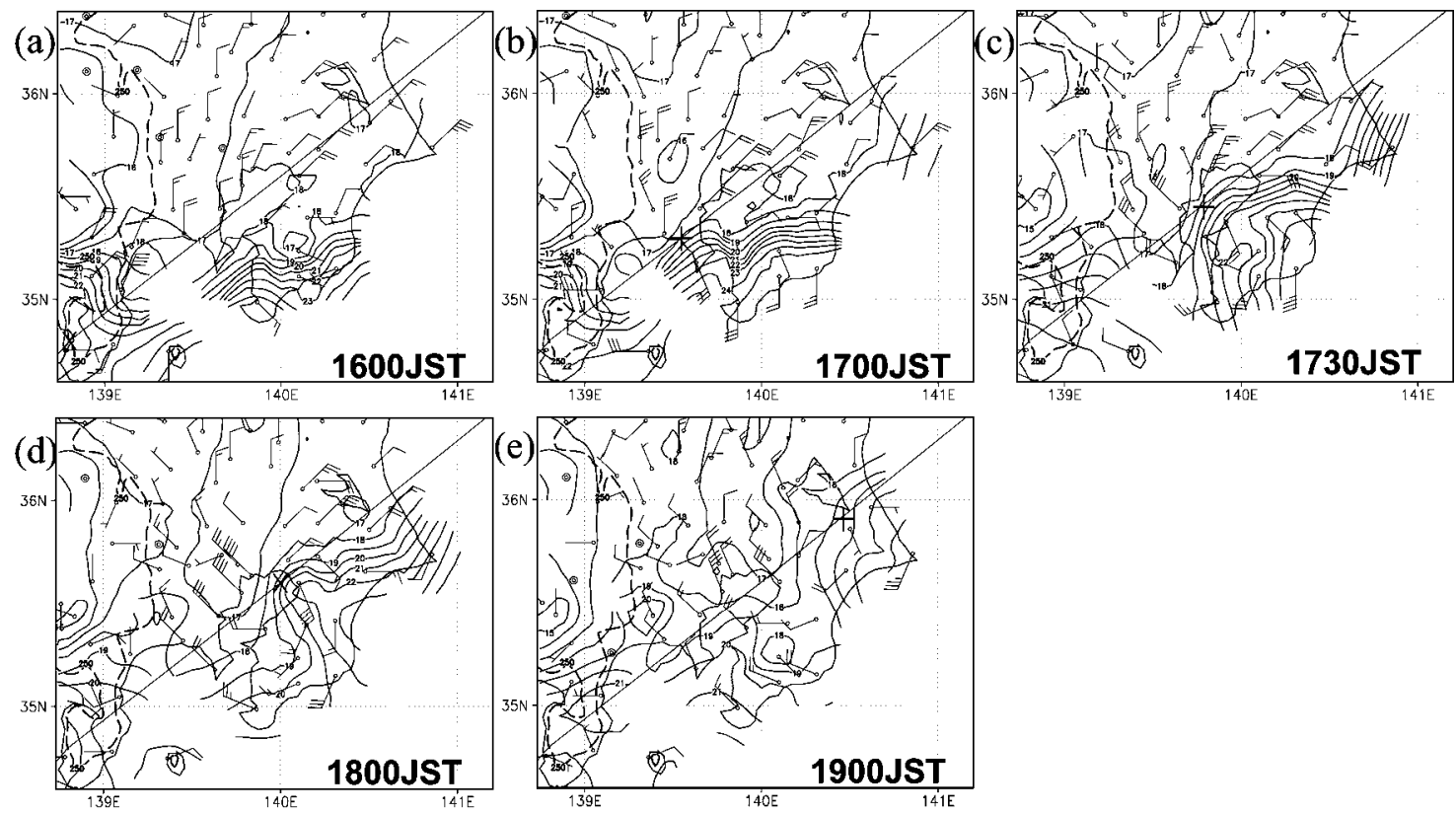

Fig. 4. The observed surface winds and temperature $\left({ }^{\circ} \mathrm{C}\right)$ from AMeDAS stations from 1600 JST to 1900 JST. The contour interval is $1^{\circ} \mathrm{C}$. The full barb and flag represent $5 \mathrm{~m} \mathrm{~s}^{-1}$ and $25 \mathrm{~m} \mathrm{~s}^{-1}$, respectively (10-min average). Solid line shows the track of Ma-on. The symbol “ $\times$ ” represents the typhoon center from the best track, and "+" is estimated one. Broken line shows $250 \mathrm{~m}$ height of the topography.

tion speed. This is quite different from the general feature of tropical cyclones. A translating symmetric typhoon vortex has stronger winds relative to the earth on the right side of the direction of motion due to the addition of the translation velocity to the storm circulation if friction is neglected. (e.g., Fujibe 1996). Considering the actual physical processes such as the frictional drag in the boundary layer, the maximum winds in the translating tropical cyclones are located more ahead (Powell 1982; Shapiro 1983; Frank 1984).

Figure 5 shows the time series of surface observation at Hiratsuka observatory (National Research Institute for Earth Science and Disaster Prevention), which is located $1 \mathrm{~km}$ offshore at the southwestern edge of the Kanto plain. Hiratsuka faces the Sagami bay to the south, while Mt. Tanzawa is located about $20 \mathrm{~km}$ to the northwest of Hiratsuka (Fig. 3). The northerly winds were observed until $1630 \mathrm{JST}$, and the strongest wind of $38.4 \mathrm{~m} \mathrm{~s}^{-1}$ (1-min average) was recorded when the wind direction started changing to the northwest, which indicates that the relative location of Hiratsuka was shifted to the rear side of Ma-on. These features are consistent with the AMeDAS data around Hiratsuka. Judging from the sequence of

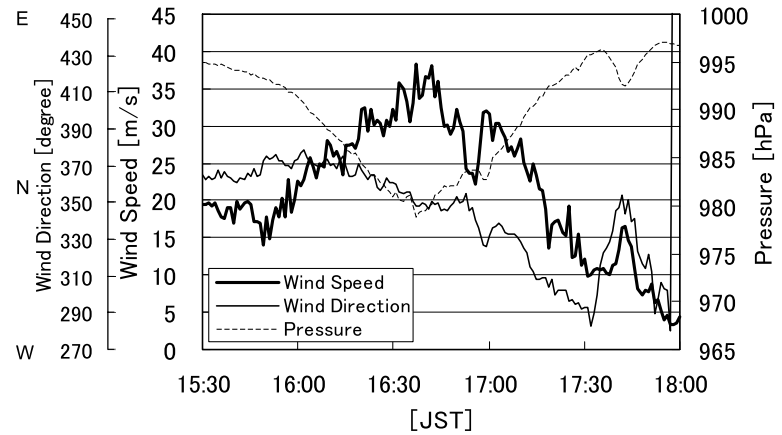

Fig. 5. Surface time series of wind speed (1-min average), wind direction and pressure at Hiratsuka observatory of National Research Institute for Earth Science and Disaster Prevention. See Fig. 3 for the location.

the pressure in Fig. 5 and the wind field from the AMeDAS data, it can be estimated that the strongest wind of $38.4 \mathrm{~m} \mathrm{~s}^{-1}$ occurred in the left-rear quadrant of the typhoon near the storm center.

The soundings for Tsukuba at 1600 JST on 9 October revealed the cold air mass was below about $950 \mathrm{hPa}$ (Fig. 6) when Ma-on was approach- 


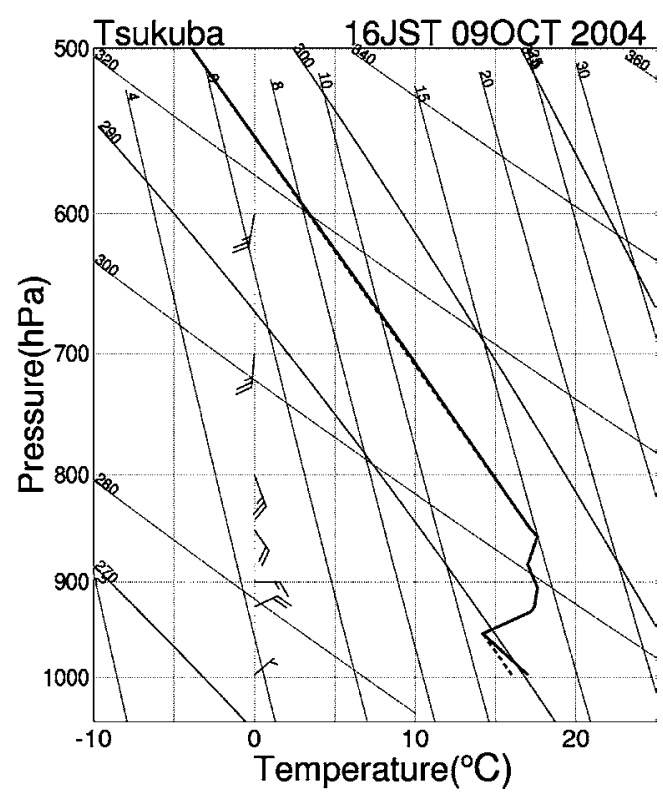

Fig. 6. Vertical profiles of temperature (thick solid line) and dew-point temperature (dashed line) observed at Tsukuba at 1600 JST on 9 October 2004. The full barb and half barb represent $10 \mathrm{~m} \mathrm{~s}^{-1}$ and $5 \mathrm{~m} \mathrm{~s}^{-1}$, respectively.

ing the Kanto plain. Above this layer, the inversion existed and the winds shifted from northeasterly to southerly drastically.

The cold northeasterly winds at low level are often observed in the east coast from the northern Japan to the Kanto region, which is on the eastern side of the mountain ranges. It is well known that this process follows the mechanism of "barrier wind” (Mass and Albright 1987; O'Connor et al. 1994) or mountain parallel motions associated with "cold air damming" in which the shallow cold air is trapped on the eastern side of a mountain range (Bell and Bosart 1988).

As described above, the characteristic of the lower-level strong winds with cold air in the northern and western quadrant of Ma-on is quite different from the general features of tropical cyclones. This paper addresses two questions in particular from the next sections.

- What are the three-dimensional structures of landfalling Ma-on around the Kanto plain?

- What is the generation mechanism of the strong winds in the left-rear quadrant of Ma-on in spite of its rapid translation?

In order to investigate these questions, numerical
Table 1. The model design

\begin{tabular}{lcc}
\hline \multicolumn{1}{c}{ Domain } & A & B \\
\hline Dimension $(\mathrm{x}, \mathrm{y})$ & $501 \times 401$ & $451 \times 529$ \\
Area coverage $\left(\mathrm{km}^{2}\right)$ & $3000 \times 2400$ & $900 \times 1056$ \\
Horizontal grid size $(\mathrm{km})$ & 6 & 2 \\
Time step (s) & 18 & 9 \\
Integration hours & $0-24$ & $6-24$ \\
\hline
\end{tabular}

simulations with high resolution were conducted.

\section{Numerical model and simulation results}

\subsection{Model description and experimental design}

Numerical reproduction of the strong winds event in the southern Kanto district was attempted using a two-way double-nested model (Mashiko and Muroi 2003). This model is based on Meteorological Research Institute/Numerical Prediction Division unified nonhydrostatic model of JMA (MRI/NPD-NHM; Saito et al. 2001). The model has fully compressible equations with a map factor, and treats the acoustic terms implicitly in both the horizontal and vertical directions. The model domains are shown in Fig. 3. The outer domain A with a $6 \mathrm{~km}$ horizontal grid spacing covers the wide area of $3000 \mathrm{~km} \times 2400 \mathrm{~km}$, while the inner domain $\mathbf{B}$ with a $2 \mathrm{~km}$ horizontal grid spacing is designed to explicitly resolve the inner-core of the typhoon and strong winds structure (Table. 1). The vertical coordinate is terrain-following and contains 50 levels with variable grid intervals of 40 $\mathrm{m}$ (near the surface) to $904 \mathrm{~m}$ (at the top of the domain) in both the domains. The model top is located at $22.7 \mathrm{~km}$. In both the domains, the bulktype cloud microphysics scheme which considers the ice phase is adopted as precipitation processes, and no convective parameterization is used. To determine the diffusion coefficients, the turbulent closure which predicts turbulent kinetic energy is employed. The time step for the domain A and B is 18 and 9 seconds, respectively.

The nesting procedure is as follows: The initial (2100 JST on 08 October 2004) conditions of the domain $\mathbf{A}$ is prepared by interpolating linearly the JMA mesoscale analysis data (MANAL) with a horizontal grid spacing of $10 \mathrm{~km}$. The ground temperature and sea surface temperature are also given by MANAL. The forecast data of JMA Regional Spectral Model (RSM) with a horizontal grid spacing of $20 \mathrm{~km}$ supplied the boundary data of the domain A every 1 hour. The inner domain 


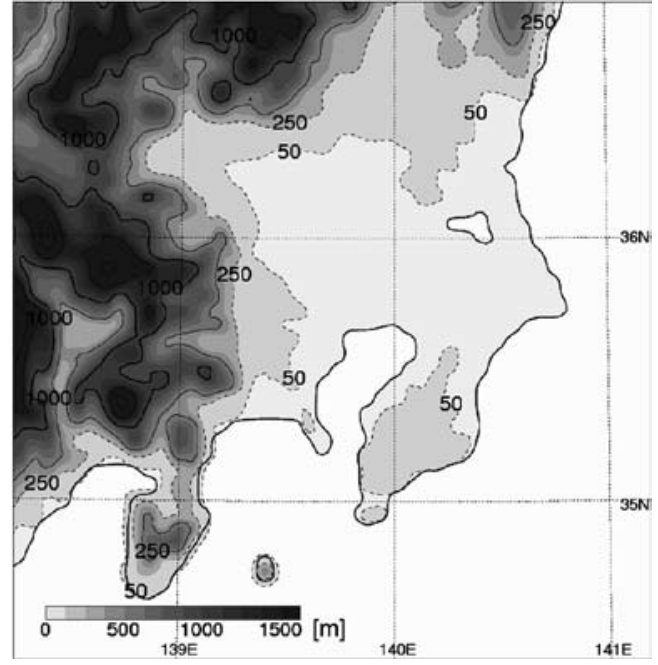

Fig. 7. The model topography around the Kanto plain for the inner domain. The solid contour interval of elevation is $500 \mathrm{~m}$, with dashed lines of 50 and $250 \mathrm{~m}$ height.

B was initialized at 6-hour forecast by interpolating the output from the domain $\mathbf{A}$, and it was integrated for 18 hours.

The topography of the domain $\mathbf{B}$ around the Kanto plain is shown in Fig. 7, which are basically same as that for the domain A since it was interpolated from that of the domain A. It illustrates that the Kanto Mountains including Tanzawa Mountains are represented in the model topography (cf., Figs. 7 and 3).

\subsection{Brief verification of simulation results}

The model generally reproduced the track of Ma-on well (Fig. 1), except for a small delay (about 20 minutes) around the southern Kanto region (cf., Figs. 4 and 12). As to the intensity, the simulated typhoon had the positive bias of MSLP at 1600 JST when Ma-on made a landfall on Izu peninsula (best track; 950hPa, model; $962 \mathrm{hPa}$ ), however, it had the negative bias near Tokyo at 1800 JST (best track; 980hPa, model; $966 \mathrm{hPa}$ ).

As for the mesoscale fields, the distribution of surface strong winds and temperature was simulated fairly well during the passage of the typhoon over the southern portion of the Kanto plain. The time series of the simulated lowest $(20 \mathrm{~m}$ above the surface) winds and pressure at the point in the vicinity of Hiratsuka for the domain $\mathbf{B}$ are shown in Fig. 8 in order to validate the simulation results

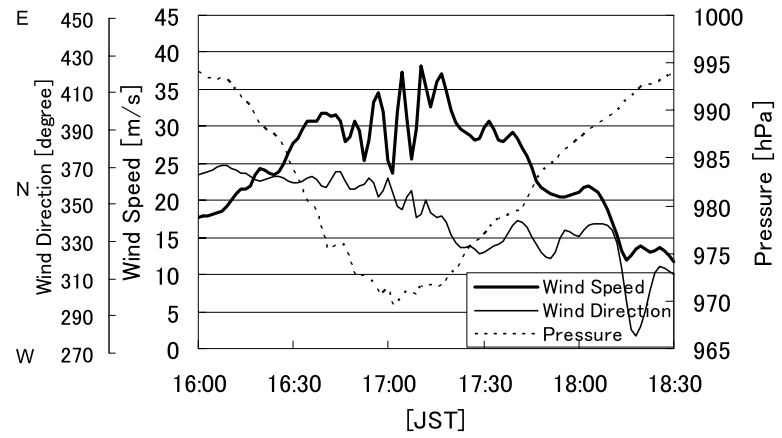

Fig. 8. The time series of the simulated lowest wind speed, wind direction and pressure at the point in the vicinity of Hiratsuka for the inner domain. Note that the abscissa axis as to time is shifted by 30 min compared to Fig. 5 .

as to the strong winds observed in the left-rear quadrant of the typhoon. The model reproduced well the characteristics of the wind speed accompanied with the changing wind direction and pressure with time except for about 20 minutes delay (cf., Figs. 8 and 5), which is probably attributable to the delay of the simulated typhoon track.

\section{Structure change of Ma-on after landfall}

\subsection{Wind field}

In order to examine the effect of typhoon landfall on the wind field, the simulated winds at low level are compared before and after landfall for the inner domain.

Figures $9 \mathrm{a}$ and $9 \mathrm{~b}$ show the wind speed with wind vectors at 1436 JST (before landfall) at a height of $250 \mathrm{~m}$ and $1000 \mathrm{~m}$, respectively. The area of the maximum winds is located on the right side, especially right-front quadrant relative to the typhoon center on both levels, which roughly agrees with the previous observational and theoretical studies with regard to the wind field of the translating tropical cyclone in the actual physical processes such as the frictional drag in the boundary layer (Powell 1982; Shapiro 1983; Frank 1984).

The wind field at 1724 JST (after landfall) is shown in Figs. 9c and 9d. In contrast to the wind distribution before landfall, the strong winds of more than $60 \mathrm{~m} \mathrm{~s}^{-1}$ can be seen clearly on the leftrear side of the typhoon center at a height of 250 m (Fig. 9c), however, they don't exist at a height of $1000 \mathrm{~m}$ (Fig. 9d). Besides, the wind direction at a height of $250 \mathrm{~m}$ in the Kanto plain after land- 
(a)

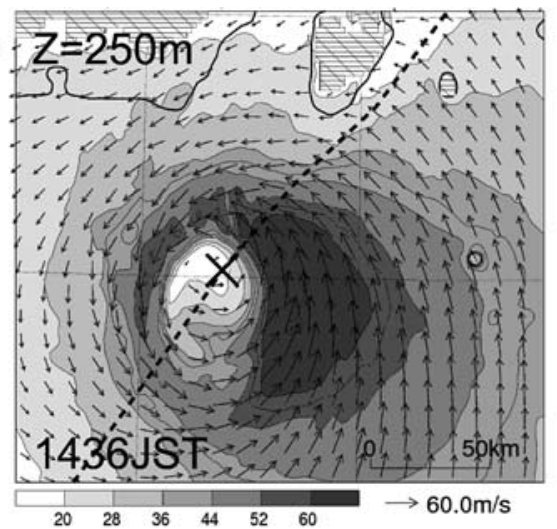

(c)

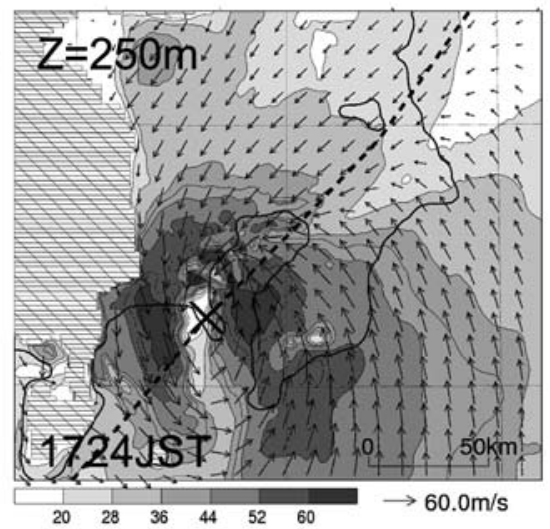

(b)

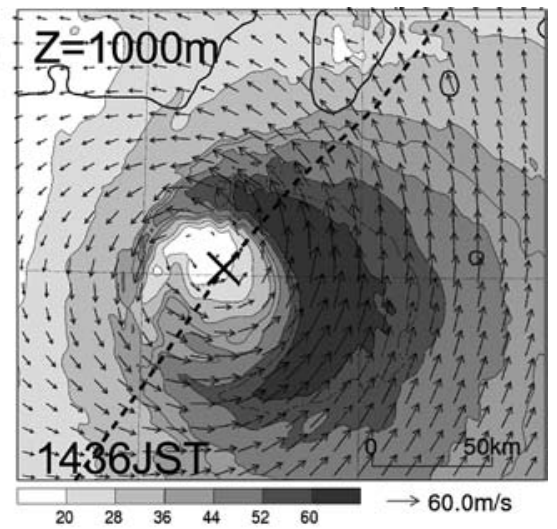

(d)

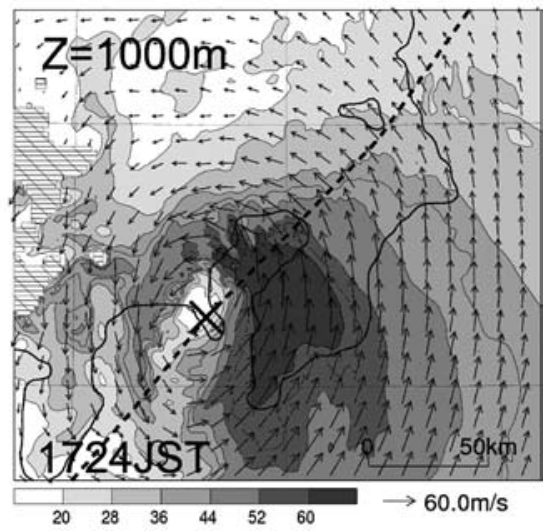

Fig. 9. Horizontal distribution of the simulated wind speed with wind vectors around the typhoon center at a height of a) $250 \mathrm{~m}$ and b) $1000 \mathrm{~m}$ at 1436 JST on 9 October (before landfall) for the inner domain. Dashed line shows the simulated typhoon track. The symbol " $\times$ " represents the simulated typhoon center. The hatched areas with no wind vector represent the model terrain above the designated levels. c)-d) As in a)-b), except for at 1724 JST (after landfall).

fall is mainly the northeasterly or the northerly (mountains orientation) near the Kanto Mountains as shown in the surface observation (cf., Figs. $9 \mathrm{c}$ and $4 \mathrm{~b}$ ). These results reveal that the strong winds in the left-rear quadrant of Ma-on are lowlevel phenomena after landfall.

\subsection{Structure of Ma-on after landfall}

Figure 10 shows the simulation result of the equivalent potential temperature (EPT) with the wind vectors at a height of $250 \mathrm{~m}$ when the strong winds on the left-rear side of the typhoon occurred. It is noteworthy feature that the northerly flow of the low EPT with cold air formed a narrowed channel, much like "gap flow", between the typhoon center and the Kanto Mountains in the west of the Kanto plain, which is quite unique in terms of relating the typhoon structure. Other no- table points are as follows: The strong winds correspond to the outflow response of the low EPT from the channel to the Sagami bay (Figs. 10 and 9c). The flow on the eastern side of the Kanto Mountains is parallel to the mountain orientation and almost perpendicular to the isobars. The southerly winds with high EPT associated with the typhoon cover only the Bousou peninsula at this level.

Figure 11a illustrates the south-north vertical cross-section of EPT with horizontal winds along AB line in Fig. 10. Clearly, the typhoon accompanied with high EPT and southerly winds moved over the low EPT area at the low level from the south. The height of the low EPT with northeasterly winds is about $500 \mathrm{~m}$ height, which agrees with the soundings at Tsukuba (Fig. 6). The strong rainfall occurred on the northern and western area of the typhoon (not shown), where the 


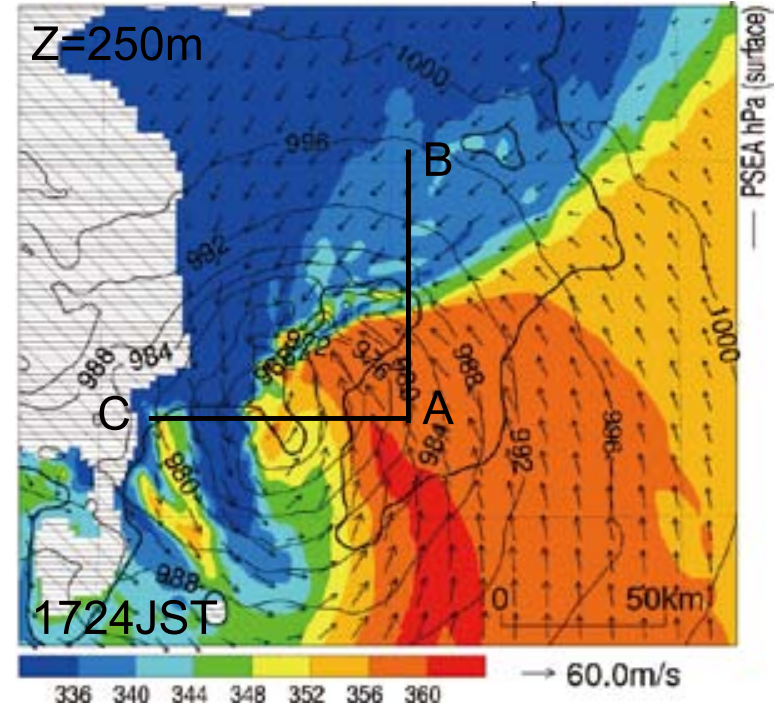

Fig. 10. Horizontal distribution of the simulated equivalent potential temperature (EPT) with wind vectors at a height of $250 \mathrm{~m}$ at 1724 JST. The contours indicate sea-level pressure with a $4 \mathrm{hPa}$ interval. The hatched areas represent the model terrain above $250 \mathrm{~m}$ height. Line segments $\mathbf{A B}$ and $\mathbf{C A}$ are the locations for the cross-sections in Fig. 11.

high EPT with the southerly winds rode on the low EPT with the northeasterly winds.

The west-east vertical cross-section along CA line crossing the typhoon center in Fig. 10 is shown in Fig. 11b. The LLJ with more than $60 \mathrm{~m}$ $\mathrm{s}^{-1}$ winds can be seen on the western side of the typhoon and it nearly corresponds to the low EPT $(<340 \mathrm{~K})$ area. The core of LLJ is located at a height of about $250 \mathrm{~m}$ around the coast.

Considering the observational data and simulation results, the question arises regarding how the low-level cold flow along the Kanto Mountains was accelerated and maximized over the Sagami bay shortly after Ma-on passed through the Sagami bay.

\section{Formation mechanism of the low-level jet (LLJ)}

\subsection{LLJ structure and time evolution}

Figures 12a-f show the time evolution of the potential temperature with wind vectors at a height of $250 \mathrm{~m}$ from 1700 JST to 1800 JST around the Kanto plain. The wind field and pressure with contours are illustrated in Figs. 12g-1. From about 1712 JST when the typhoon center reached the Sagami bay, the cold air mass $(\theta<295 \mathrm{~K})$ started flowing significantly with the northerly winds from the Kanto plain to the Sagami bay. The Kanto Mountains and the central typhoon formed a narrowed channel of the cold air, which is like the gap flow structure (Figs. 12b-d). Note that this case includes significant temporal transition in accordance with the changing environmental conditions caused by the typhoon movement, unlike the common gap flow events. The outflow response of the cold air from the narrowed channel corresponds to the formation of the LLJ with more than $60 \mathrm{~m} \mathrm{~s}^{-1}$ winds over the Sagami bay in the left-rear quadrant of the typhoon around 1724 JST (Fig. 12i). The LLJ is not located at the head
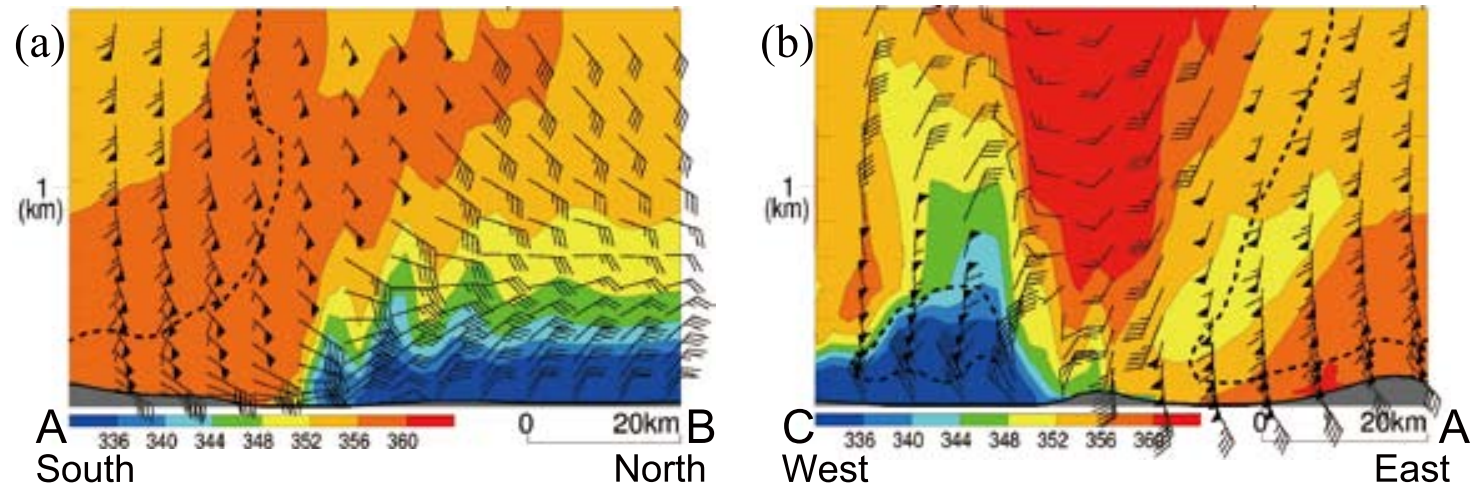

Fig. 11. (a) The south-north vertical cross-section along line $\mathbf{A B}$ and (b) west-east vertical cross-section along line CA in Fig. 10 of the simulated EPT with horizontal wind vectors at 1724 JST. The full barb and flag represent $10 \mathrm{~m} \mathrm{~s}^{-1}$ and $50 \mathrm{~m} \mathrm{~s}^{-1}$, respectively. Wind speed of $60 \mathrm{~m} \mathrm{~s}^{-1}$ is contoured with the dashed line. 
(a)

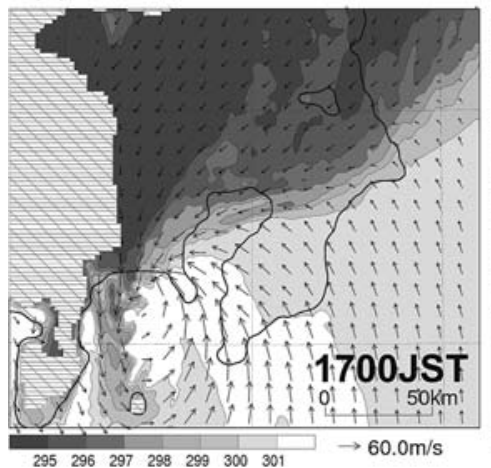

$(\mathrm{g})$

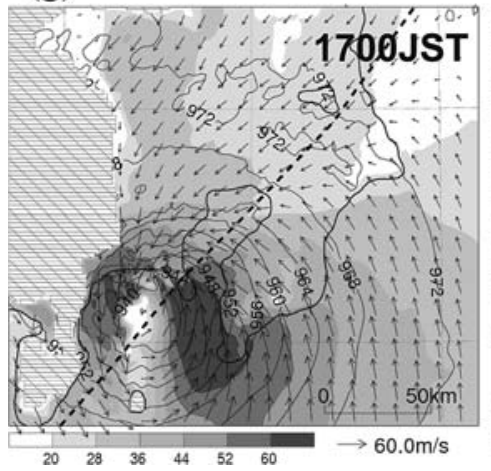

(b)

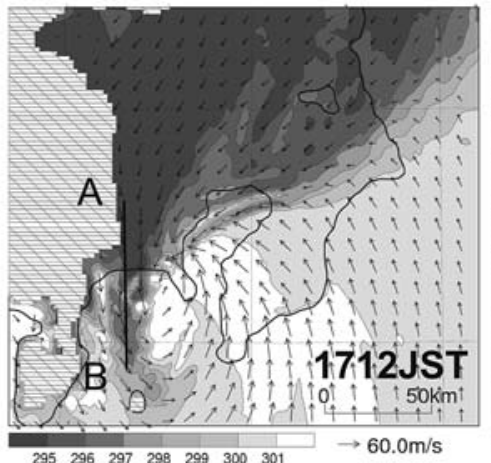

(h)

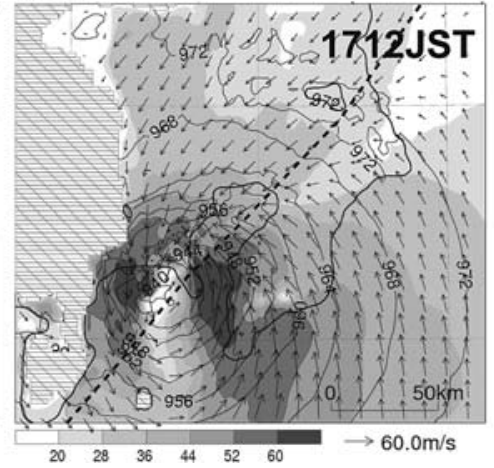

(c)

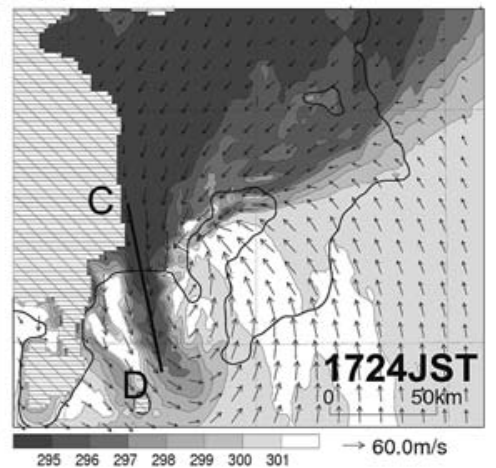

(i)

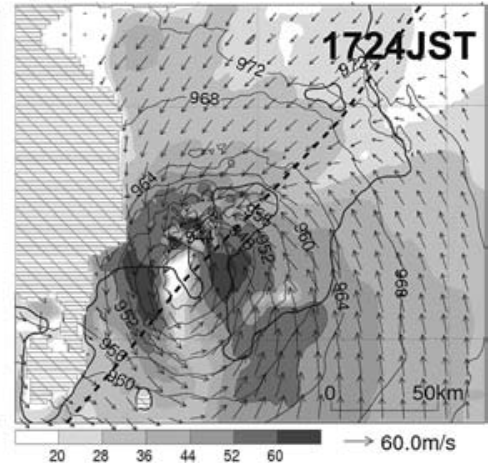

Fig. 12. Time evolution of (a)-(f) the simulated potential temperature and (g)-(l) wind speed with wind vectors at a height of $250 \mathrm{~m}$ from 1700 JST to 1800JST at an interval of 12 minutes. The line segments $\mathbf{A B}$ in (b) and $\mathbf{C D}$ in (c) indicate the location for the cross sections in Fig. 13a and 13b, respectively. The contours in (g)-(l) indicate pressure at this level with a $4 \mathrm{hPa}$ interval. Dashed line shows the simulated typhoon track.

of the cold flow. Therefore, this event cannot be simply identified with the topographically trapped density current shown by Mass and Albright (1987). After 1748 JST the channel of the cold air became wide and blurry (Figs. 12e and 12f), and the maximum wind in the left-rear quadrant of the typhoon got weaker (Figs. 12k and 12l) as the typhoon passed away.

Figures 13a and 13b illustrate the vertical crosssection along line $\mathbf{A B}$ (Fig. 12b) and $\mathbf{C D}$ (Fig. 12c) at 1712 JST and 1724 JST, respectively. At 1712 JST when the LLJ started forming, the depth of the low-level cold air $(\theta<296 \mathrm{~K})$ was about 400 $\mathrm{m}$ height on the upstream in the cross-section AB. At the exit of the narrowed channel, the flow with low $\theta$ shallowed, descended and accelerated to more than $60 \mathrm{~m} \mathrm{~s}^{-1}$. The isotachs got close to the surface down the stream and wind speed increased near the surface around the exit of the narrowed channel. The behavior of the simulated strong winds and potential temperature is roughly consistent with the previous studies of gap flow (Arakawa 1969; Lackmann and Overland 1989; Colle and Mass 2000; Sharp and Mass 2002). At 1724 JST when the LLJ became prominent, the flow with low $\theta$ of $296 \mathrm{~K}$ deepened to approximately $400 \mathrm{~m}$ height around the coast with no descent of isentropic surface as shown in the cross-section CD (Fig. 13b).

Note that these snapshots of vertical cross-section cannot necessarily reflect the gap flow structure because the flow is not stationary. Therefore, the trajectories analysis is required in order to investigate the dynamics of the LLJ (see Section $6.2)$.

\subsection{Trajectory analysis}

Figures 14a-c illustrate the 48-min backward and 12-min forward trajectories starting at 1724 JST from an array of points at the Sagami bay 
(d)

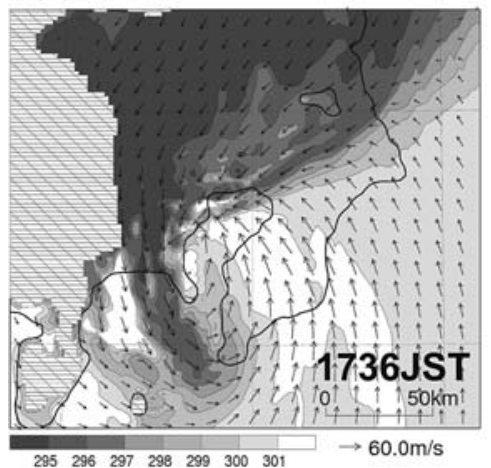

(j)

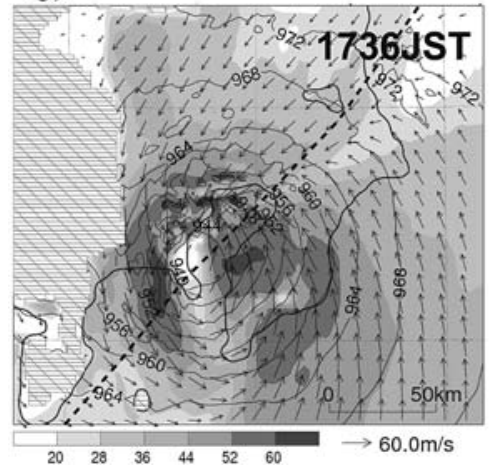

(e)

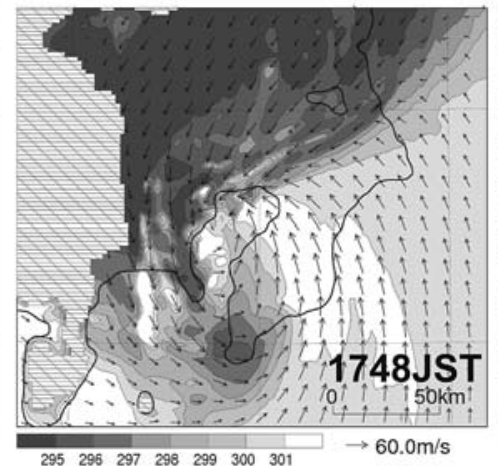

(k)

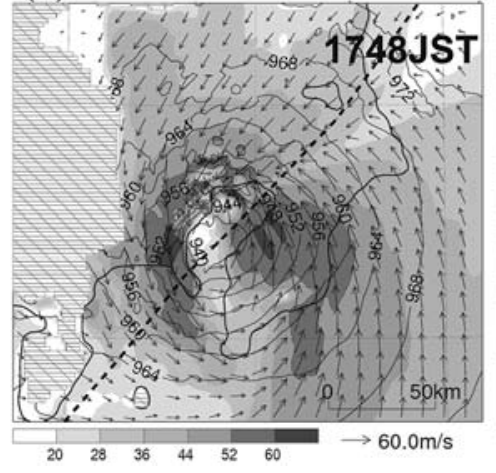

(f)

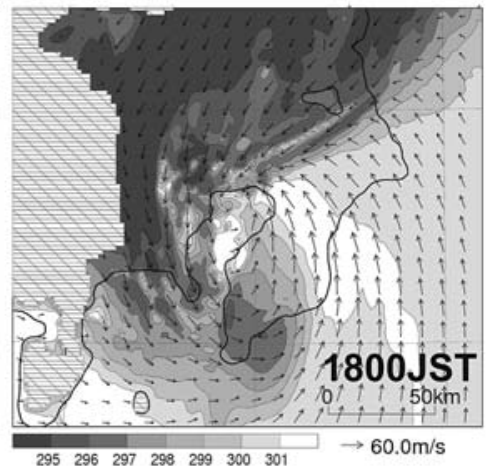

(1)

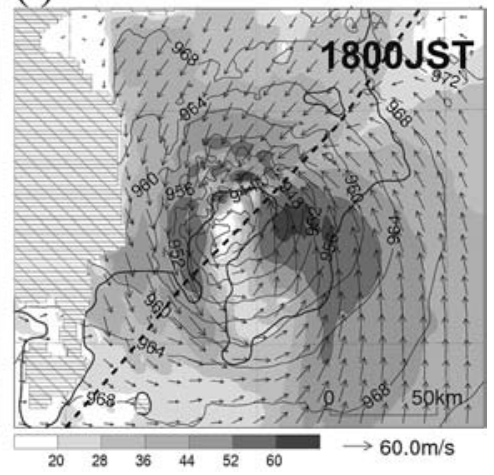

Fig. 12. Continued

where the strong winds were observed in the leftrear quadrant of the typhoon. The analysis was conducted using the grid point data of 10 seconds intervals interpolated from 90 seconds model output. The velocity components were interpolated linearly to trajectory locations. We employed the leap-frog scheme for the time integration of the trajectory. Checks were performed to verify that the trajectories gave a true path of the air flow. The horizontal velocity of the trajectory in the core of the LLJ was calculated integrating Lagrangian acceleration of the model output from 1636 JST. The discrepancy was less than $2 \mathrm{~m} \mathrm{~s}^{-1}$ throughout the trajectory path when it was compared with the actual horizontal velocity at the trajectory location.

As to the trajectories originating at $80 \mathrm{~m}$ and $240 \mathrm{~m}$ above the surface over the Sagami bay (Figs. 14a and 14b), the air parcels generally move along the eastern side of the Kanto Mountains. They came from the inland of the Kanto plain. They accelerated while moving southward parallel to the Kanto Mountains. After the parcels passed near the Tanzawa Mountains at the southern tip of the Kanto Mountains, salient subsidence, spreading and acceleration occurred toward the Sagami bay. They subsequently decelerated and some of them ascended near the head of the cold airflow. The maximum wind is observed over the Sagami bay at the forth parcel from the west around the originating points in Fig. 14b (hereafter this parcel is referred to as TR-4). The low-level subsidence, spreading and acceleration at the exit of the narrowed channel of the cold air are consistent with the previous studies of gap wind (e.g., Colle and Mass 2000). The parcel of the western edge at origin in Fig. 14b came from the higher point $(593 \mathrm{~m})$ over the Bousou peninsula in the warm sector at 1636 JST. It swirled around the typhoon center and subsided rapidly from above $1000 \mathrm{~m}$ in the lee of the Tanzawa Mountains. The high $\theta(>301 \mathrm{~K})$ existed around the path of this air parcel over the western Sagami bay at a height of $250 \mathrm{~m}$ (Figs. 12c and 12d). These characteristics indicate that the isentropic surface descended rapidly in the lee of the Tanzawa Mountains (not 

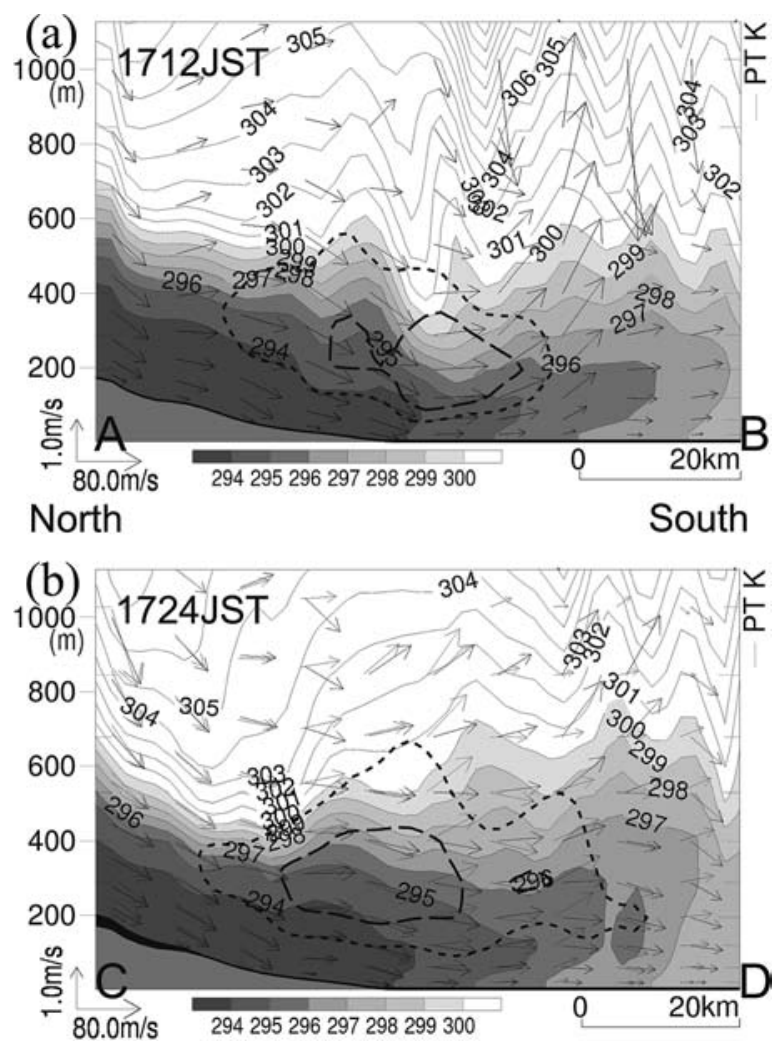

Fig. 13. The vertical cross-section along (a) line $\mathbf{A B}$ in Fig. $12 \mathrm{~b}$ and (b) line $\mathbf{C D}$ in Fig. 12c of the simulated potential temperature at 1712 JST and at 1724 JST, respectively. Dotted and dashed lines denote wind speed of $52 \mathrm{~m} \mathrm{~s}^{-1}$ and $60 \mathrm{~m}$ $\mathrm{s}^{-1}$, respectively. shown), which is associated with downslope winds (e.g., Saito 1994). In the meanwhile, the trajectories originating at $1130 \mathrm{~m}$ (Fig. 14c) represent the general feature of tropical cyclones. They are swirling and ascending around the typhoon center, and most of them come from the lower level. The result of the trajectory analysis agrees with the vertical structure of Ma-on that moved over the low-level cold air in the Kanto plain as indicated Section 5.2.

Figures $15 \mathrm{a}-\mathrm{c}$ show the evolution of the height of isentropic surface $(\theta=296 \mathrm{~K})$ from 1712 JST to 1724 JST with the track of the TR-4. The isentropic surface $(296 \mathrm{~K})$ is higher in the western part and inland of the Kanto plain. The cold air mass became shallower and spread from the vicinity of Tanzawa Mountains to the Sagami bay especially at 1712 JST and 1718 JST (Figs. 15a and 15b). The pressure field was largely distorted in accordance with the gradient of isentropic surface near the Tanzawa Mountains. The isentropic surface of $296 \mathrm{~K}$ gradually became shallower at the inland of the Kanto plain and deepened from the coast to the Sagami bay as the typhoon center moved northeastward. Concerning TR-4, when the parcel accelerated with a descending motion and passed near the Tanzawa Mountains at 1718 JST, large southward decline of isentropic surface existed there (Fig. 15b). It appears that southward pressure gradient force along the wind direction due to the variation in cold-layer thickness worked and accelerated the parcel. This is evaluated quantitatively in Section 6.3. At 1724 JST when the LLJ
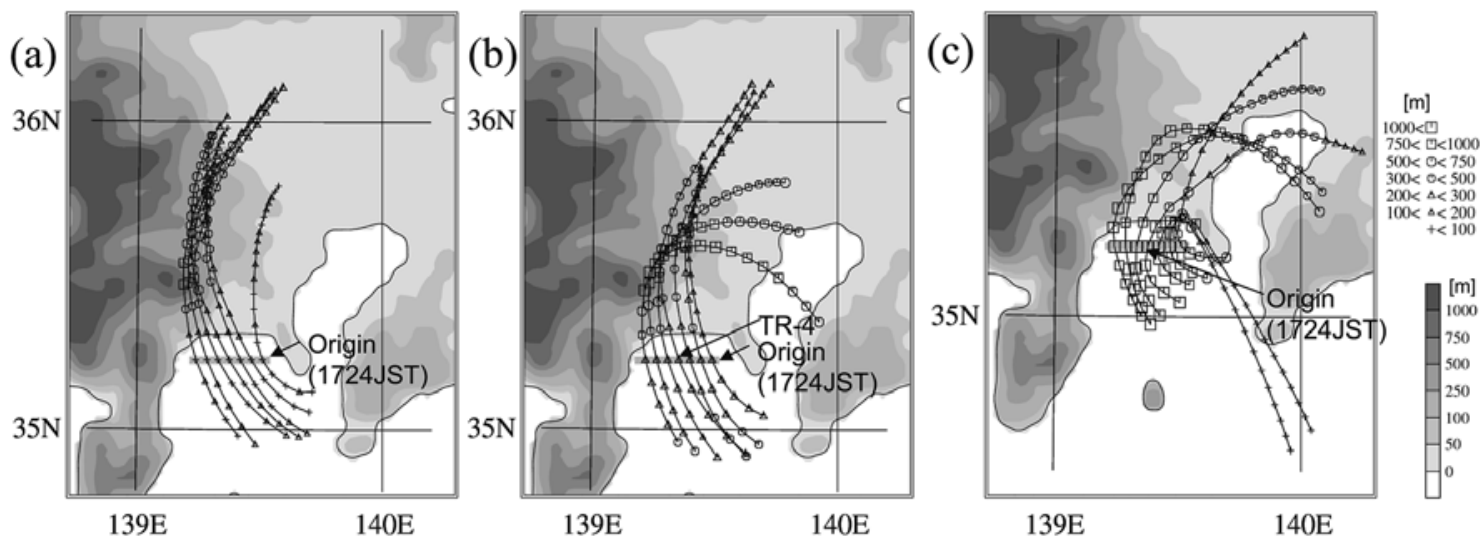

Fig. 14. Analyzed trajectories for 48-min backward and 12-min forward originating from a) 80, b) 240 and c) $1130 \mathrm{~m}$ height over the Sagami Bay at 1724 JST 9 October. The markers represent the air parcel locations at an interval of 3 minutes showing the height with their size. The model terrain is shaded. 
(a)

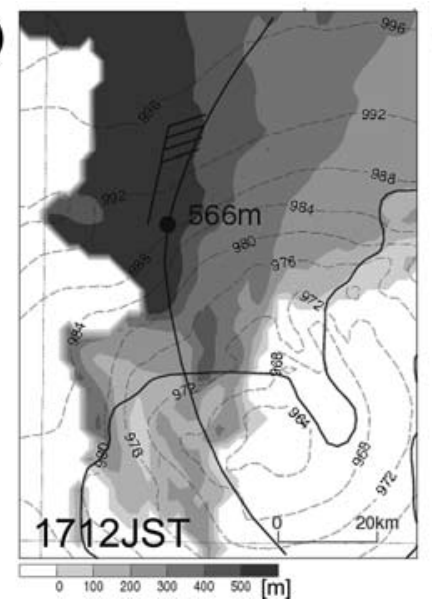

(b)

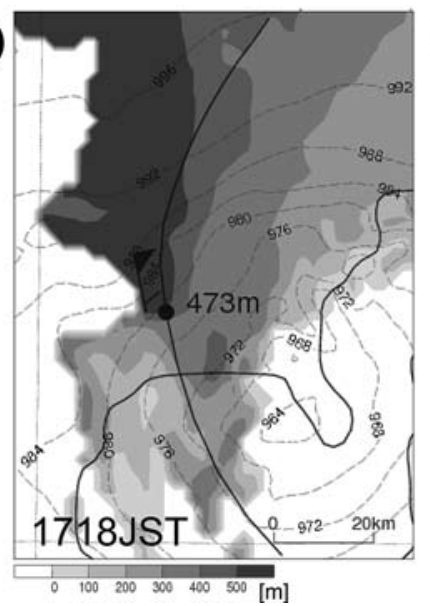

(c)

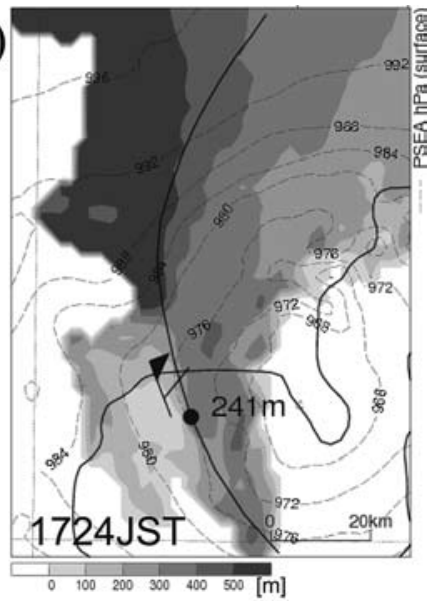

Fig. 15. Height of isentropic surface (296 K) at (a) 1712, (b) 1718 and (c) 1724 JST. Solid line shows the trajectory of TR-4 with the wind arrow (left side) and the height (right side) at the corresponding time. The full barb and flag represent $10 \mathrm{~m} \mathrm{~s}^{-1}$ and $50 \mathrm{~m} \mathrm{~s}^{-1}$, respectively. Dashed lines denote the sea-level pressure with a contour interval of $4 \mathrm{hPa}$.

was maximized, there was almost no decline of the isentropic surface along the wind direction in the core of the cold flow near the coast (Fig. 15c).

\subsection{Momentum budget diagnostics for the LLJ}

To understand the dynamics of the LLJ over the Sagami bay just after the passage of Ma-on, individual terms of the horizontal momentum equation on the terrain-following coordinate $\left(z^{*}\right)$ in the numerical model were output at the interval of 90 seconds. The horizontal momentum equation along the horizontal wind direction $(x)$ is expressed as follows,

$$
\begin{aligned}
& \frac{D V}{D t}=\underbrace{-\frac{1}{\rho}\left(\frac{\partial p}{\partial x}\right)_{z^{*}}}_{\mathrm{PGF}_{\mathrm{sp}}} \frac{-\frac{1}{\rho}\left(\frac{z^{*}-H}{H-z_{s}} \frac{\partial z_{s}}{\partial x}\right)\left(\frac{\partial p}{\partial z^{*}}\right)_{x}}{\mathrm{PGF}_{\mathrm{cnv}}}+\text { Dif } \\
& z^{*}=\frac{H\left(z-z_{s}\right)}{H-z_{s}}
\end{aligned}
$$

where $V, \rho$, and $p$ represent horizontal wind velocity, density and pressure, respectively. $H$ is the model-top height, and $z_{s}$ is the surface height. The term of left-hand side of (1) is the total derivative of the velocity with respect to time. The first term of the right-hand side of (1) represents the pressure gradient force on the model surface. In this experiment $H$ is set to $22.7 \mathrm{~km}$, therefore, low-level model surfaces can be assumed to be parallel to the terrain surface approximately. The notation of the first term is $\mathrm{PGF}_{\text {slp }}$. The second one $\left(\mathrm{PGF}_{\mathrm{cnv}}\right)$ is conversion term of the vertical coordinate from $z$ to $z^{*}$. The third term (DIF) includes subgridscale turbulent mixing and computational diffusion. Due to the along-wind analysis, the Coriolis force associated with horizontal velocity does not work. To be exact, the equation includes Coriolis term associated with the upward motion and curbature term, however, they can be abbreviated due to the trivial values.

Figure $16 \mathrm{a}$ shows the time series of the individual terms of the horizontal momentum equation (1) for the trajectory of TR-4 (see Section 6.2) which passed through the core of the strong winds over the Sagami bay. Clearly, the $\mathrm{PGF}_{\text {slp }}$ is dominant and accelerates the parcel. The $\mathrm{PGF}_{\text {slp }}$ is always leeward (positive values) until around 1724 JST (the starting time of the trajectory analysis), so that the strongest winds formed over the Sagami bay then. The DIF is relatively weak, but after the parcel reached the Sagami bay it became a little more effective due to the active turbulent mixing.

When the parcel passed near the Tanzawa Mountains from 1712 JST to 1721 JST, the salient accelerations occurred in accordance with the strong $\mathrm{PGF}_{\text {slp. This momentum budget analysis }}$ reveals that the southward pressure gradient near the Tanzawa Mountains contributed largely to the LLJ formation. This is evident from Figs. 12h, 15a and $15 \mathrm{~b}$, which show that the isobars intersect the mountains almost straight and densely near the Tanzawa Mounatains and that the wind vectors 

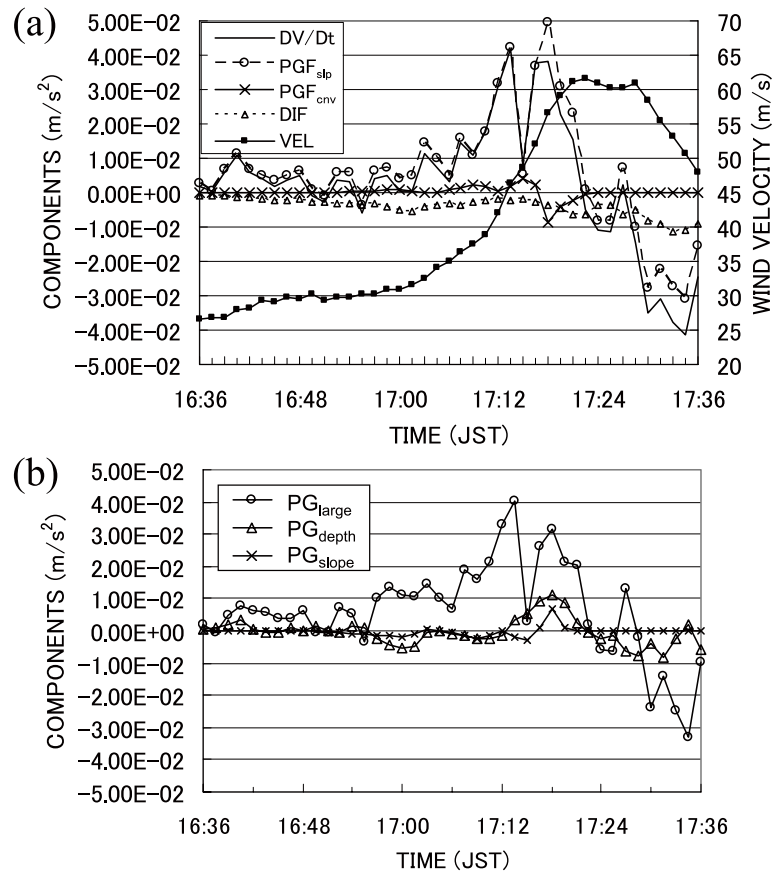

Fig. 16. Time series of along-wind components of (a) the horizontal momentum equation (1) and (b) individual terms of pressure gradient force equation (2) calculated for the trajectory TR-4. The wind velocity (VEL) of TR-4 is also shown in (a).

are nearly orthogonal to the isobars.

As to this $\mathrm{PGF}_{\text {slp }}$ retrieved from the model output, it is logically of great interest to identify the contribution of each physical mechanism to this driving force. Following Mahrt (1982), the $\mathrm{PGF}_{\text {slp }}$ at a height of $z$ in the lower cold layer can be decomposed into three components by assuming hydrostatic approximation for the motion perpendicular to the ground:

$$
\begin{aligned}
& \mathrm{PGF}_{\text {slp }}(z) \cdot \cos \alpha \\
& =\underbrace{\frac{g}{\theta_{0}} \sin \alpha-\cos \alpha \frac{g}{\theta_{0}} \frac{\partial(\bar{d} h)}{\partial s}-\frac{1}{\rho} \frac{\partial p_{a m b}}{\partial s}} \underbrace{\mathrm{PG}_{\text {large }}}_{\mathrm{PG}_{\text {slope }}} \\
& \bar{d}=\frac{1}{h} \int_{z}^{h}\left(\theta_{0}-\theta\right) d z
\end{aligned}
$$

where $d$ is the potential temperature deficit, the difference in potential temperature at any point between the lower cold layer and the ambient atmosphere. The term $s$ is distance along the terrain surface, $\alpha$ the terrain slope, $h$ the depth of the cold layer, $g$ gravity force and $\theta_{0}$ the average potential temperature in the cold layer. $P_{a m b}$ in the third term of the right hand side refers to the ambient environmental pressure.

On the right hand side of (2), the first term $\left(\mathrm{PG}_{\text {slope }}\right)$ is caused by cold, stably stratified air over sloping terrain. The second term $\left(\mathrm{PG}_{\text {depth }}\right)$ is due to the variation in cold-layer thickness along the wind direction. The third term represents the large-scale pressure gradient $\left(\mathrm{PG}_{\text {large }}\right)$. Although the $\mathrm{PGF}_{\text {slp }}$ includes the weight of water content and dynamical effect, we neglect them in (2) since they are relatively small.

We evaluated the individual terms following Parish and Cassano (2003). The $\mathrm{PG}_{\text {slope }}$ and $\mathrm{PG}_{\text {depth }}$ terms can be computed from the vertical profile of potential temperature at each grid point. The potential temperature deficit $d$ can be determined at each level for every grid point by extrapolation of the potential temperature profile in the free atmosphere down to the surface (see Fig. 8 in Parish and Cassano 2003). The thickness of the cold air mass is limited to approximately the lowest 1000 $m$ based on sounding data (Fig. 6) and the model data (Fig. 11 and Fig. 13) in this study. Therefore, the layer from $z^{*}=1030 \mathrm{~m}$ (model level $\mathrm{L}=11$ ) to $3500 \mathrm{~m}(\mathrm{~L}=20)$ above the surface is assumed to represent the ambient atmosphere. The ambient potential temperature in the low-level cold layer can be calculated at each grid point by extrapolating the least linear fit to the ambient potential temperature above that, and the integrated potential temperature deficit $\left(\mathrm{PG}_{\text {depth }}\right)$ can be evaluated. The PGlarge is determined as a residual term in (2).

Figure $16 \mathrm{~b}$ shows the time series of the individual terms in (2) calculated for the TR-4. In this analysis, $z$-direction is not perpendicular to the ground but vertical to the horizontal surface, however, this approximate treatment has validity because $\tan \alpha$ is considerably small (less than 0.05) throughout the trajectory. The $\mathrm{PG}_{\text {large }}$ is a dominant term and consistently positive until about 1724 JST since Ma-on was approaching the southern Kanto region and a strong southward pressure gradient existed there. The peak of $\mathrm{PG}_{\text {large }}$ is around 1712 JST when the parcel was approaching the Tanzawa Mountains. Although the $\mathrm{PG}_{\text {depth }}$ and $\mathrm{PG}_{\text {slope }}$ are much smaller than the $\mathrm{PG}_{\text {large }}$, they contributed effectively to the $\mathrm{PGF}_{\text {slp }}$ around 1718 JST when the parcel passed near the Tanzawa Mounatains. Therefore, the large $\mathrm{PGF}_{\text {slp }}$ worked there significantly at that time and created the LLJ 
leeward over the Sagami bay. These results are consistent with the trajectory analysis (Fig. 14b) and the time change of the declined height of isentropic surface (Fig. 15), which represent that the cold air started outflowing explosively with the descending flow toward the Sagami bay when the typhoon center passed over the Sagami Bay. Compared to the previous study in the middle of the valley in Iran (Liu et al. 2000), the individual terms are quite larger ( $\sim 2$ order). However, the total effect of $\mathrm{PG}_{\text {depth }}$ and $\mathrm{PG}_{\text {slope }}$ through the path around the Tanzawa Mountains contributed only about 5 $\mathrm{m} \mathrm{s}^{-1}$ increase to the wind velocity, which is nearly equivalent amount to the typical gap wind event (e.g., Colle and Mass 2000). After 1730 JST, the $\mathrm{PG}_{\text {large }}$ rapidly caused negative effect as shown in Figs. $12 \mathrm{j}$ and $12 \mathrm{k}$. The wind vectors cross isobars outward from the storm center on the rear side of the typhoon. The parcel significantly decelerated in accordance with the effect of the turbulent mixing.

Thus the LLJ over the Sagami Bay after the passage of Ma-on is mainly supported by the largescale field $\left(\mathrm{PG}_{\text {large }}\right)$ when the low-level cold air was traveling along the eastern side of the mountain range. Moreover, the locally generated mesoscale forcing due to the thickness variation of cold layer $\left(\mathrm{PG}_{\mathrm{depth}}\right)$ took effect around the exit of the narrowed channel of the cold air. Therefore, this can be identified as the general mechanism of gap wind.

\section{Sensitivity experiments}

Sensitivity tests were conducted to investigate the effect of the topography and the low-level cold air on the wind field.

Figure 17 shows the model topography of the experiment in which the Kanto Mountains on the western side of the Kanto plain were partly removed from the control experiment (CNTL). As shown in Fig. 18a, the position of the typhoon center and the central pressure are almost the same as those of CNTL. However, the wind field shows a quite different pattern from that of CNTL (Fig. 18). The winds immediately decelerate around the coast of the Sagami bay. They are more than $15 \mathrm{~m}$ $\mathrm{s}^{-1}$ weaker than those of CNTL over the Sagami bay. The wind maximum on the left-rear side of the typhoon is located around the coast, and the LLJ does not form over the Sagami bay. The trajectory analysis reveals that the parcels in the cold flow move parallel to each other (Fig. 19).

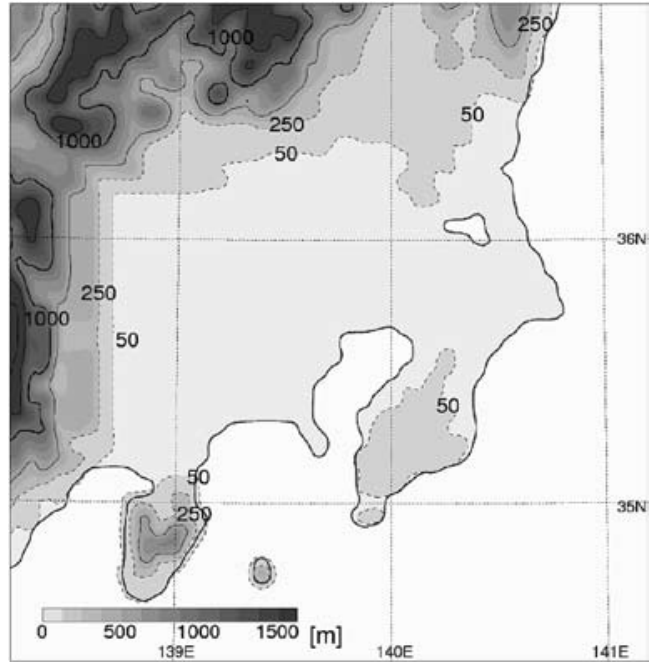

Fig. 17. As in Fig. 7 except for the experiment in which the Kanto Mountains were partly removed on the western side of the Kanto plain.

Note that salient subsidence, spreading and acceleration toward the Sagami bay does not occur. The trajectory paths are more southward than those of CNTL around the coast of the Sagami bay (cf., Figs. 19 and 14b). Figure 20 shows the height of the isentropic surface $(296 \mathrm{~K})$ at 1718 JST, which represents the thickness of the lowlevel cold air. Due to the elimination of the Kanto Mountains, the area of the cold flow is widened on the western side of the typhoon and the narrowed channel of the cold air does not form, so that the variation in cold-layer thickness is considerably small (cf., Figs. 20 and 15b). Apparently, the effects of $\mathrm{PG}_{\text {slope }}$ and $\mathrm{PG}_{\text {depth }}$ work little in this experiment. Besides, the wind direction from the coast to the Sagami bay shifts outward from the typhoon center (more southward) compared to that of CNTL. The winds have cross-isobar component and the $\mathrm{PGF}_{\text {slp }}$ significantly works negative against the wind direction over the Sagami Bay (cf., Figs. 21 and 16a). These effects brought major difference in the winds field over the Sagami bay between this experiment and CNTL. It indicates that the relative position between the typhoon center and the mountains range is crucial for the LLJ formation.

In order to confirm the effect of the low-level cold air, we conducted an experiment in which the sea surface temperature and the ground tempera- 
(a)

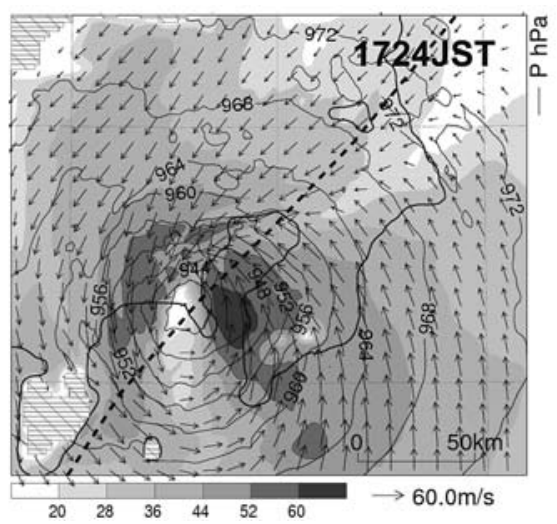

(b)

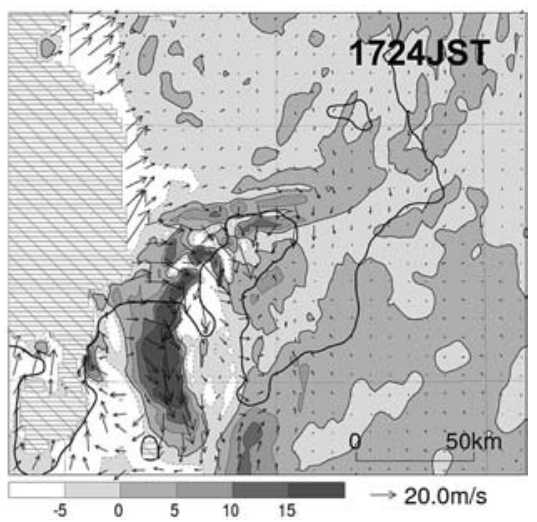

Fig. 18. (a) As in Fig. 12i except for the experiment in which the Kanto Mountains were partly removed. (b) The difference of wind field between CNTL and the experiment in which the Kanto Mountains were partly removed (CNTL minus sensitivity experiment).

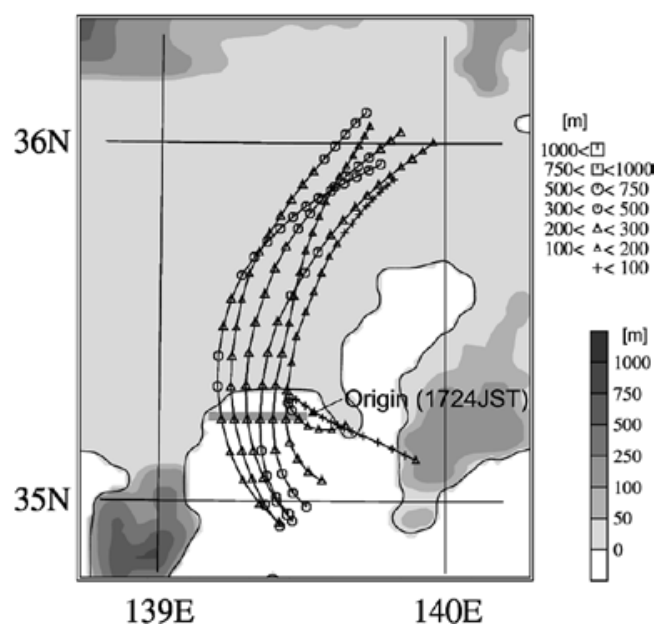

Fig. 19. As in Fig. 14b except for the experiment in which the Kanto Mountains were partly removed.

ture were risen to $26^{\circ} \mathrm{C}$ around the Kanto region using a $6.5 \mathrm{~K} \mathrm{~km}^{-1}$ lapse rate for the ground elevation. In this experiment, the low-level cold air does not exist in the Kanto plain, therefore, the typhoon makes landfall keeping its structure throughout the lower and middle troposphere. Figures 22a and $22 \mathrm{~b}$ show the potential temperature and wind field around the Kanto plain, respectively. The trajectory paths are illustrated in Fig. 23. The typhoon has general features of tropical cyclones, which are high potential temperature in the core area and swirling winds around the typhoon center accompanied with maximum wind on the right

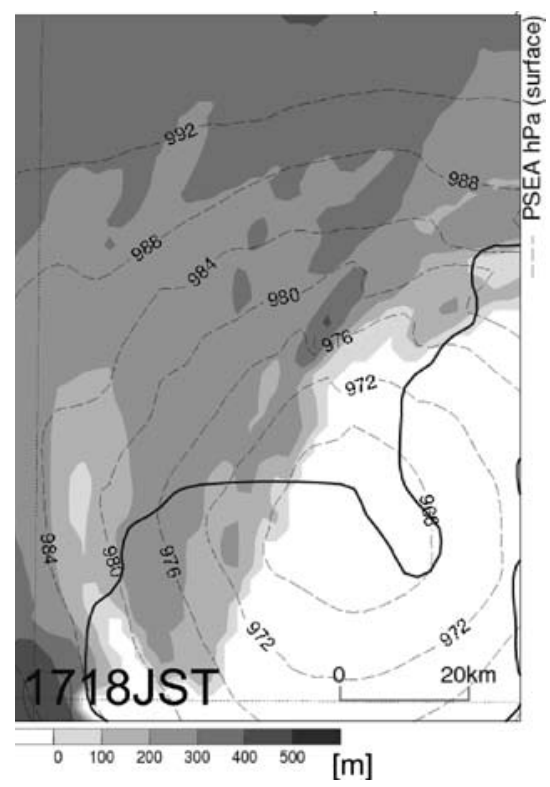

Fig. 20. Height of isentropic surface (296 K) at 1718 JST for the experiment in which the Kanto Mountains were partly removed. Dashed lines denote the sea-level pressure with a contour interval of $4 \mathrm{hPa}$.

side of storm motion. The topography effect on the wind field is considerably limited. The wind speed increases slightly on the narrow region in the left-rear quadrant of the typhoon. This result coincides with the case of Typhoon Mawar (2005) which had almost same track and intensity as those of Ma-on (Fig. 24). When Mawar hit the Kanto plain on 26 August 2005, low-level cold air 


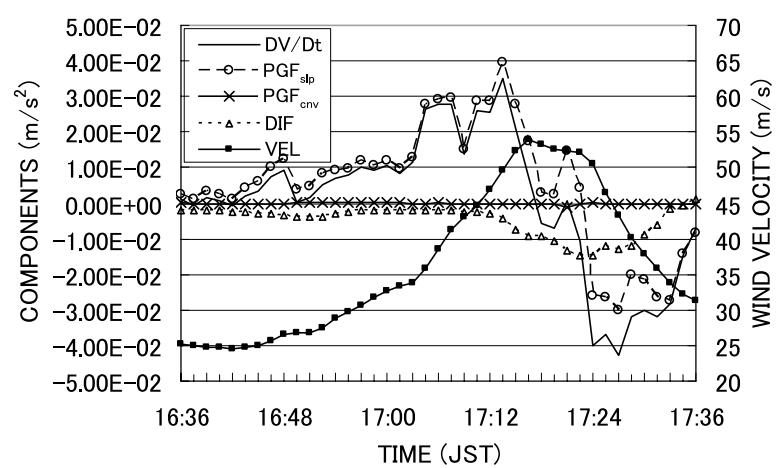

Fig. 21. As in Fig. 16a except for the experiment in which the Kanto Mountains were partly removed.

(a)

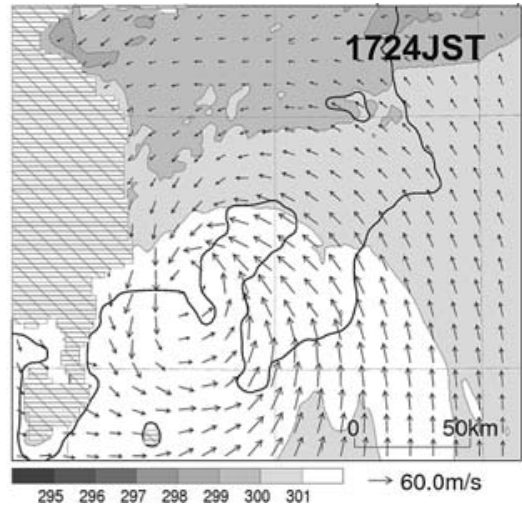

did not exist there (not shown). MAWAR had no strong winds on the left-rear quadrant during the passage over the southern Kanto region (Fig. 25). The wind direction changed from west to east constantly, which indicates that MAWAR kept the general feature of tropical cyclones with the swirling wind field around the typhoon center over the Kanto region.

\section{Summary and conclusions}

On 9 October 2004, Typhoon Ma-on hit the southern Kanto district in eastern Japan and caused hazardous winds. Ma-on is characterized by the strong winds in the left-rear quadrant near

(b)

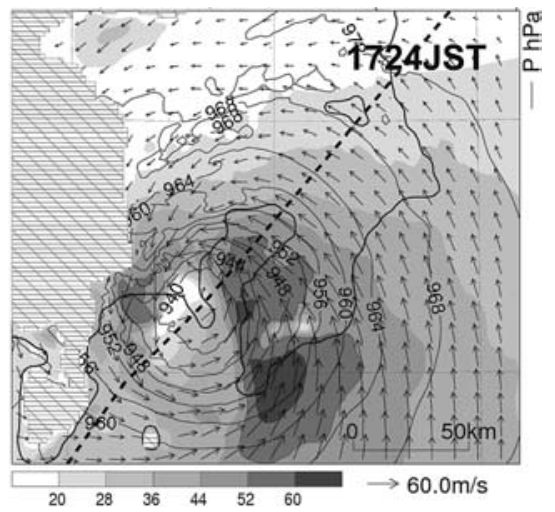

Fig. 22. (a) As in Fig. 12c, (b) as in Fig. 12i except for the experiment in which the sea surface temperature and ground temperature were risen to $26^{\circ} \mathrm{C}$.

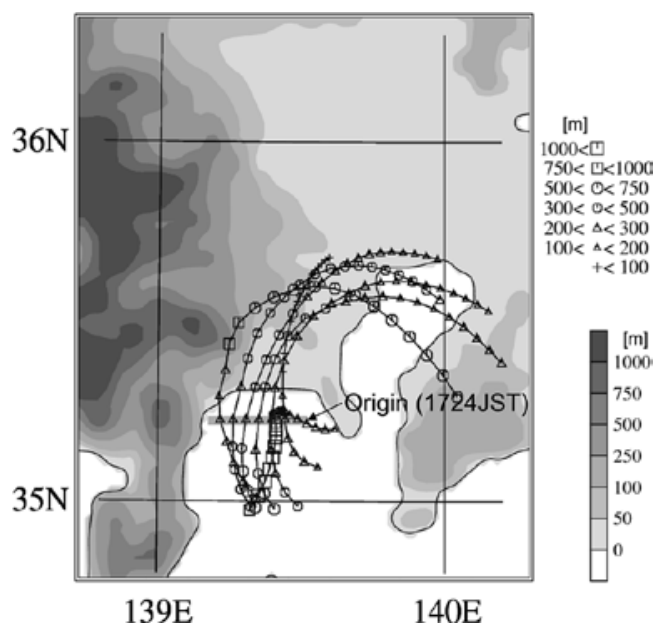

Fig. 23. As in Fig. 14b except for the experiment in which the sea surface temperature and ground temperature were risen to $26^{\circ} \mathrm{C}$.

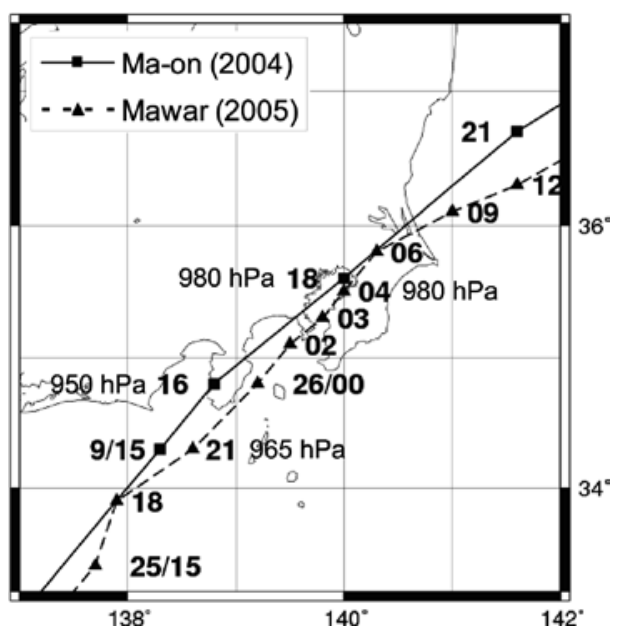

Fig. 24. Comparison of the best track between Ma-on (2004) and Mawar (2005). Numerals show the corresponding time (hour or date/hour) and MSLP. 


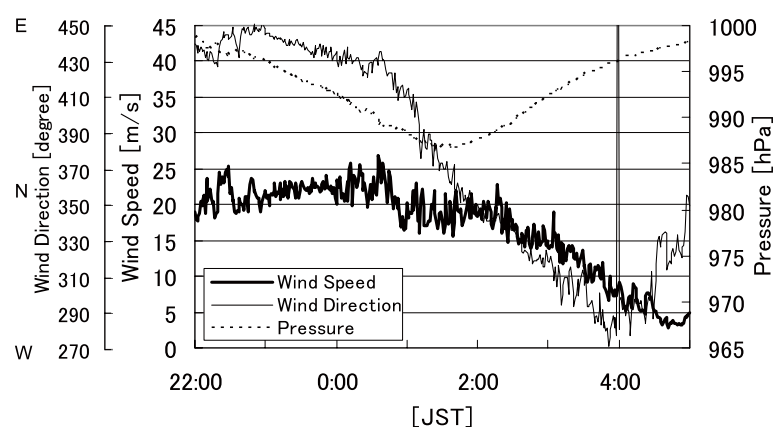

Fig. 25. As in Fig. 5 except for the case of Mawar (2005) from 2200 JST on 25 August to 0500 JST on 26, 2005.

the typhoon center during its passage over the southern Kanto district in spite of the rapid translation speed of about $70 \mathrm{~km} \mathrm{~h}^{-1}$. Strong northerly winds (10-min average) of about $20 \mathrm{~m} \mathrm{~s}^{-1}$ were observed in the southern Kanto region when the typhoon center was translating from the Sagami bay to Tokyo bay. The wind of $38.4 \mathrm{~m} \mathrm{~s}^{-1}$ (1-min average) was recorded at the Hiratsuka observatory located offshore on the Sagami bay.

When Ma-on was approaching the Kanto plain, the stationary front existed to the south of eastern Japan. The low-level synoptic winds were the northeasterly with cold air in the Kanto plain. In the eastern side of the Kanto Mountains, the wind direction turned parallel (northerly) to the mountains orientation. The low-level cold air with northerly or northeasterly winds was almost sustained during the passage of Ma-on over the Kanto region. The wind and temperature fields around Maon on the Kanto region were quite different from the general features of the tropical cyclones.

In order to elucidate the structure of landfalling Ma-on and the formation mechanism of the strong winds on the left-rear quadrant of Ma-on, the highresolution simulations with a horizontal grid spacing of $2 \mathrm{~km}$ were conducted. This study is the first attempt to simulate the real phenomena of severe mesoscale event near the center of tropical cyclone. The model successfully reproduced the observed wind and temperature fields.

The simulation results reveal that the strong winds on the left-rear quadrant of Ma-on were low-level phenomena after the landfall. The LLJ formed over the Sagami bay just after the typhoon center passed there. The typhoon accompanied with high EPT moved over the low-level cold air from the south in the Kanto region. When the typhoon center reached the Sagami bay, the Kanto Mountains and the central typhoon formed a narrowed channel of the northerly cold flow at low level, much like "gap flow". Around the Tanzawa Mountains, the wind vectors in the channel were nearly orthogonal to the isobars which intersected the mountain range densely almost at right angles. The LLJ corresponds to the outflow response of the cold air from the narrowed channel to the Sagami bay. The wind velocity is maximized at a height of about $250 \mathrm{~m}$. At the exit of the narrowed channel, the flow with cold air mass became shallower and widened leeward. These are essentially identical to the general features of gap wind (Arakawa 1969; Lackmann and Overland 1989; Colle and Mass 2000; Sharp and Mass 2002).

The trajectory analysis originating at the LLJ shows that the parcels came from the inland of the Kanto plain and moved southward parallel to the Kanto Mountains. After they passed near the Tanzawa Mountains at the southern tip of the Kanto Mountains, the salient subsidence, spreading and acceleration occurred toward the Sagami Bay. The horizontal momentum budget analysis for the TR-4 originating at the LLJ reveals that the pressure gradient force on the terrain surface $\left(\mathrm{PGF}_{\text {slp }}\right)$ was dominant and contributed largely to the LLJ formation near the Tanzawa Mountains. The $\mathrm{PGF}_{\text {slp }}$ as a driving force to the LLJ was decomposed following Mahrt (1982) and Parish and Cassano (2003). The LLJ over the Sagami Bay after the passage of Ma-on was mainly supported by the largescale southward pressure gradient $\left(\mathrm{PG}_{\text {large }}\right)$ on the Kanto plain, which was formed by approaching Ma-on. However, locally generated mesoscale forcing due to the decreasing depth of cold layer $\left(\mathrm{PG}_{\mathrm{depth}}\right)$ worked around the exit of the narrowed channel of the cold air. Therefore, it can be identified as the general mechanism of gap wind.

The sensitivity experiments in which the topography and surface temperature were changed reveal that the low-level cold air as well as the relative position between the high mountainous topography and the typhoon is essential for the formation of the LLJ. The topography of the Kanto Mountains affects not only the wind speed but also the wind direction from the coast to the Sagami bay, which influences the formation of the LLJ.

A landfalling tropical cyclone often has remarkable asymmetric wind structures and induces haz- 
ardous winds due to the various mechanisms. The other severe windstorms with horizontal scales of $\sim 1 \mathrm{~km}$ occurred on the shear line between the eastern side of the low-level cold flow and the warm southerly winds around the Tokyo bay. They will be reported on another article.

This study is first to document the strong winds caused by the gap wind mechanism due to the typhoon structure and the topography. Observational studies are expected to verify the detailed mesoscale structures like this event in the future.

\section{Acknowledgements}

The author would like to thank two anonymous reviewers for their valuable and constructive comments that greatly improved the manuscript. Thanks are extended to Dr. T. Kato, Mr. S. Hayashi and his colleagues of MRI for their helpful comments and their support to conduct the numerical simulations. The author also thanks to National Research Institute for Earth Science and Disaster Prevention for providing meteorological data at Hiratsuka observatory. The numerical simulations in this study were performed using a NEC SX-6 super computer system of MRI.

\section{References}

Arakawa, S., 1969: Climatological and dynamical studies on the local strong winds, mainly in Hokkaido, Japan. Geophys. Mag., 34, 359-425.

Arakawa, S., 2006: Gap wind and its brief review. Tenki., 53, 161-166 (in Japanese).

Bell, G.D. and L.F. Bosart, 1988: Appalachian cold-air damming. Mon. Wea. Rev., 116, 137-161.

Bender, M.A., 1997: The effect of relative flow on the asymmetric structure in the interior of hurricanes. J. Atoms. Sci., 54, 703-724.

Black, M.L., J.F. Gamache, F.D. Marks, C.E. Samsury, and H.E. Willoughby, 2002: Eastern pacific Hurricanes Jimena of 1991 and Olivia of1994: The effect of vertical shear on structure and intensity. Mon. Wea. Rev., 130, 2291-2312.

Blackwell, K.G., 2000: The evolution of Hurricane Danny (1997) at landfall: Doppler-observed eyewall replacement, vortex contraction/intensification, and low-level wind maxima. Mon. Wea. Rev., 128, 4002-4016.

Chen, Y. and M.K. Yau, 2003: Asymmetric structures in a simulated lanfalling hurricanes. J. Atoms. Sci., 60, 2294-2312.

Colle, B.A. and C.F. Mass, 2000: High-resolution observations and numerical simulations of easterly gap flow through the strait of Juan de Fuca on 9 -10 December 1995. Mon. Wea. Rev., 128, 2398-
2422.

Frank, W.M., 1984: A composite analysis of the core of a mature hurricane. Mon. Wea. Rev., 112, 24012420 .

Frank, W.M. and E.A. Ritchie, 2001: Effects of vertical wind shear on the intensity and structure of numerically simulated hurricanes. Mon. Wea. Rev., 129, 2249-2269.

Fujibe, F., 1992: Mesoscale fronts in the Kanto plain associated with southeast winds accompanying tropical storms: Examples and statistics. Tenki., 39, 35-44 (in Japanese).

Fujibe, F., A. Tabata, and K. Akaeda, 1995: Features of surface wind fields in the south Kanto plain during the passage of a tropical storm and a mesoscale cold front in its northern portion. Tenki., 42, 3-12 (in Japanese).

Fujibe, F., 1996: On the formulae for wind distribution in a translating typhoon. Tenki., 43, 671-680 (in Japanese).

Fujibe, F., N. Kitabatake, K. Bessho, and S. Hoshino, 2006: Comparison of surface-wind fields between Typhoon 0418 (Songda) and Typhoon 9119 (Mireille) in Western Japan. Pap. Meteor. Geophys., 57, 1-9.

Fujita, T.T., 1981: Tornadoes and downbursts in the context of generalized planetary scales. J. Atoms. Sci., 38, 1511-1534.

Jones, S.C., 1995: The evolution of vortices in vertical shear. I: Initially barotropic vortices. Quart. J. Roy. Meteor. Soc., 121, 821-851.

Kitabatake, N., 2002: Extratropical transformation of Typhoon Vicki (9807): Structural change and the role of upper-tropospheric disturbances. $J$. Meteor. Soc. Japan, 80, 229-247.

Klein, P.M., P.A. Harr, and R.L. Elsberry, 2000: Extratropical transition of western North Pacific tropical cyclones: An overview and conceptual model of the transformation stage. Wea. Forecasting, 15, 373-395.

Knupp, K.R., J. Walters, and M. Biggerstaff, 2006: Doppler profile and radar observations of boundary layer variability during the landfall of tropical storm Gabrielle. J. Atoms. Sci., 63, 234251.

Lackmann, G.M. and J.E. Overland: 1989: Atmospheric structure and momentum balance during a gap-wind event in Shelikof Strait, Alaska. Mon. Wea. Rev., 117, 1817-1833.

Liu, M., D.L. Westphal, T.R. Holt, and Q. Xu, 2000: Numerical simulation of a low-level jet over complex terrain in southern Iran. Mon. Wea. Rev., 128, 1309-1327.

Liu, Y., D.-L. Zhang, and M.K. Yau, 1997: A multiscale numerical study of Hurricane Andrew (1992). Part I: Explicit simulation and verification. Mon. Wea. Rev., 125, 3073-3093. 
Mahrt, L., 1982: Momentum balance of gravity flows. J. Atoms. Sci., 39, 2701-2711.

Mashiko, W. and C. Muroi, 2003: Development of a two-way multiply-nested movable mesh typhoon model using the cloud resolving nonhydrostatic model. CAS/JSC WGNE, 33, 5.22-5.23.

Mass, C.F. and M.D. Albright, 1987: Coastal southerlies and alongshore surges of the west coast of North America: Evidence of mesoscale topographically trapped response to synoptic forcing. Mon. Wea. Rev., 115, 1707-1738.

O'Connor, W.P., D.H. Bromwich, and J.F. Carrasco, 1994: Cyclonically forced barrier winds along the Transantarctic Mountains near Ross Island. Mon. Wea. Rev., 122, 137-150.

Overland, J.E., 1984: Scale analysis of marine winds in straits and along mountains coasts. Mon. Wea. Rev., 112, 2530-2534.

Parish, T.R. and J.J. Cassano, 2003: Diagnosis of the katabatic wind influence on the wintertime Antarctic surface wind field from numerical simulations. Mon. Wea. Rev., 131, 1128-1139.

Powell, M.D., 1982: The transition of the Hurricane Frederic boundary-layer wind field from the open Gulf of Mexico to landfall. Mon. Wea. Rev., 110, 1912-1932.

Powell, M.D., 1987: Changes in the low-level kinematic and thermodynamic structure of Hurricane Alicia (1983) at landfall. Mon. Wea. Rev., 115, 75 -99 .

Powell, M.D., P.P. Dodge, and M.L. Black, 1991: The landfall of Hurricane Hugo in the Carolinas: surface wind distribution. Wea. Forecasting, 6, 379399.

Powell, M.D. and S.H. Houston, 1996: Hurricane
Andrew's landfall in south Florida. Part II: Surface wind fields and potential real-time applications. Wea. Forecasting, 11, 329-349.

Powell, M.D. and S.H. Houston, 1998: Surface wind fields of 1995 Hurricanes Erin, Opal, Luis, Marilyn, and Roxanne at landfall. Mon. Wea. Rev., 126, 1259-1273.

Saito, K., 1992: Shallow water flow having a lee hydraulic jump over a mountain range in a channel of variable width. J. Meteor. Soc. Japan, 70, 775782 .

Saito, K., 1994: A numerical study of the local downslope wind "Yamaji-Kaze" in Japan. Part 3: -Numerical simulation of the 27 September 1991 windstorm with a non-hydrostatic multi-nested model-. J. Meteor. Soc. Japan, 72, 301-329.

Saito, K., T. Kato, H. Eito, and C. Muroi, 2001: Documentation of the Meteorological Research Institute/Numerical Predic-tion Division Unified Nonhydrostatic Model. Technical Re-ports of the MRI, 42, 133 pp.

Shapiro, L.J., 1983: The asymmetric boundary-layer flow under a translating hurricane. J. Atoms. Sci., 40, 1984-1998.

Sharp, J. and C. Mass, 2002: Columbia Gorge gap flow. Bull. Amer. Meteor. Soc., 83, 1757-1762.

Wakimoto, R.M. and P.G. Black, 1994: Damage survey of Hurricane Andrew and its relationship to the eyewall. Bull. Amer. Meteor. Soc., 75, 189-200.

Yau, M.K., Y. Liu, D.-L. Zhang, and Y. Chen, 2004: A Multiscale Numerical Study of Hurricane Andrew (1992). Part VI: Small Scale Inner-Core Structure and Wind Streaks. Mon. Wea. Rev., 132, 1410-1433. 